\title{
Durability of bond in NSM CFRP-concrete systems under different environmental conditions
}

\author{
Pedro Fernandes ${ }^{\mathrm{a}}$, José Sena-Cruz ${ }^{\mathrm{a}}$, José Xavier $^{\mathrm{b}, \mathrm{c}}$, Patrícia Silva $^{\mathrm{a}}$, Eduardo Pereira $^{\mathrm{a}}$, José Cruz $^{\mathrm{a}}$ \\ a ISISE, University of Minho, Department of Civil Engineering, Guimarães, Portugal \\ ${ }^{\mathrm{b}}$ INEGI, University of Porto, Faculty of Engineering, Porto, Portugal \\ ${ }^{\mathrm{c}}$ CITAB, University of Trás-os-Montes and Alto Douro, Vila Real, Portugal
}

\begin{abstract}
This paper addresses the durability of bond between concrete and carbon fibre reinforced polymer (CFRP) strips installed according to the near-surface mounted (NSM) technique (NSM CFRP-concrete systems) under the effects of two main groups of environmental conditions: (i) laboratory-based ageing conditions; (ii) real outdoor ageing conditions. The bond degradation was evaluated by carrying out direct pullout tests on aged specimens that were previously subjected to distinct environmental conditions for different periods of exposure. Moreover, the degradation of the mechanical properties of the involved materials was investigated. The digital image correlation (DIC) method was used to document the evolution of the deformation fields at the surface over the whole region of interest consisting of concrete and epoxy adhesive at the ligament region. This information supported the discussion about the evolution of the bond resistant mechanism developed in NSM CFRP-concrete specimens during testing, as well as the assessment of the bond quality of the system. In general, the results obtained from the durability tests conducted have shown that the different exposure environments, which may be considered as quite severe, did not result in significant damage on NSM CFRP-concrete system. The maximum decrease of about $12 \%$ on bond strength was obtained for real outdoor environments. Conversely, a maximum increase of $8 \%$ on bond strength was obtained on the specimens exposed to the temperature cycles between $-15{ }^{\circ} \mathrm{C}$ and $+60{ }^{\circ} \mathrm{C}$. DIC allowed to document the stress transfer mechanisms established between the CFRP and the concrete substrate, revealing the crack patterns and the influence widths of the CFRP reinforcement strips, which were shown to be important for avoiding group effect when using multiple parallel strengthening CFRP strips.
\end{abstract}

\footnotetext{
${ }^{1}$ Corresponding author: jsena@,civil.uminho.pt
} 
Fernandes, P.; Sena-Cruz, J.; Xavier, J.; Silva, P.; Pereira, E.; Cruz, J.R. (2018) "Durability of bond in NSM CFRP-concrete systems under different environmental conditions." Composites Part B, 138: 19-34.

\section{KEYWORDS}
A. Carbon fibre
B. Debonding
B. Environmental degradation
D. Mechanical testing

Near-surface mounted systems 
Fernandes, P.; Sena-Cruz, J.; Xavier, J.; Silva, P.; Pereira, E.; Cruz, J.R. (2018) "Durability of bond in NSM CFRP-concrete systems under different environmental conditions." Composites Part B, 138: 19-34.

\section{INTRODUCTION}

During the last fifteen years, the near-surface mounted (NSM) strengthening technique using fibre reinforced polymers (FRP) as reinforcing material has been considered as one of the most effective to increase the load carrying capacity of concrete members. In the NSM FRP strengthening system, FRP bars are inserted into pre-cut grooves opened in the concrete cover of the elements to be strengthened. The FRP reinforcement is bonded to concrete with an appropriate groove filler, which typically consists of an epoxy adhesive. Research to date has been mainly focused on the overall structural behaviour when these systems are employed, such as the flexural and shear strengthening effectiveness, energy dissipation capacity of beam-column joints and the various parameters that affect the bond performance of the available NSM systems [1-3]. Conversely, some other key issues, such as the durability and the long-term performance of NSM FRP systems, still remain insufficiently characterized and require further research. As the bond behaviour plays a key role in ensuring the effectiveness of the NSM FRP strengthened systems, a clear understanding of the durability and long-term performance is critical for designing the structural strengthening system considering their entire service life.

The lack of a comprehensive, validated, and easily accessible database regarding the durability and long-term performance of FRP systems used in civil infrastructure applications has been identified as a critical obstacle to the widespread use of these systems/materials by civil/structural designers and practitioners [4]. Despite the successful use of FRP composites and epoxy adhesives in advanced industries such as aerospace, there are critical differences, since the corresponding environmental conditions, substrates and involved loads, as well as the type of materials and the manufacturing processes involved are clearly distinct [5]. Therefore, the available information based on the past experience of these industries cannot be directly applied to the case of FRP/epoxy systems used for the structural rehabilitation or civil infrastructure applications [6]. For these reasons, durability and life-cycle cost assessment of NSM systems in the context of civil engineering applications are regarded as critical to allow taking full advantage of this new technology and its uptake by the industry.

In order to predict the long-term performance of FRP strengthening systems, it is critical to understand the factors that affect their durability, as well as the degradation mechanisms that occur both in each of the individual materials and the ones that result from the interaction between the FRP and the substrate, during service life. Several factors are known to affect the durability of the materials and of the strengthening techniques which involve the use of FRPs. Examples are the choice of the constituent materials, the method adopted to design the FRP strengthening system, the techniques employed to install and allow the curing of the FRPs, the existence of effective maintenance 
Fernandes, P.; Sena-Cruz, J.; Xavier, J.; Silva, P.; Pereira, E.; Cruz, J.R. (2018) "Durability of bond in NSM CFRP-concrete systems under different environmental conditions." Composites Part B, 138: 19-34.

plans and the environmental exposure conditions throughout their service life $[4,7,8]$. The rate and type of degradation can be quite different depending on the material, environmental conditions and exposure time [9].

Typically, most of the durability studies found in the literature were performed by using accelerated ageing tests in harsh environments at the laboratory [10] or, in some cases, in real exposure conditions. In fact, the adoption of real ageing conditions represents long testing periods, essentially equivalent to the expected service life of the material or system. Although more time consuming, the testing in real ageing conditions can provide unparalleled understanding of the real degradation phenomena [11]. The research related to this topic is still scarce, and the current state of knowledge in this regard is rather limited, as generally acknowledged [1].

The durability of FRP based strengthening systems is predominantly dependent on the bond behaviour. The existing knowledge on the bond durability of NSM FRP-concrete systems is limited. In fact, only a few works can be found in the literature. The effect of temperature (thermal and freeze-thaw cycles) on the durability has been investigated, e.g. [7, 12-15] through bond pullout tests. In general, these studies reported that the bond strength increased for temperatures below the glass transition temperature $\left(T_{g}\right)$ of the adhesive (bonding agent) and decreased for temperatures equal to or beyond $T_{g}$. The results indicated also that the $T_{g}$ of the epoxy adhesive had a significant influence on the failure modes obtained $[12,16]$. The effect of moisture exposure through wet-dry cycles has been shown to lead to reductions of $12 \%$ on bond strength of the system [17], while negligible changes in load carrying capacity (ultimate bond strength) were found after the exposing the specimens to freeze-thaw cycles and water immersion [7]. The slight reduction on bond strength due to moisture environments exposure is attributed to water absorption (plasticization phenomenon), which affect the mechanical properties of the epoxy and the adhesion between materials (breakage of interfacial bonds) [18]. The temperature variation and moisture exposure are considered as important environmental degradation factors that can affect detrimentally the durability of RC structures, in the framework of strengthening systems with FRP materials.

The vast majority of the existing research on the durability of FRP based strengthening systems is mostly dedicated to the study of the externally bonded reinforcement (EBR), e.g. [19-22]. Given the lack of numerous studies focussing NSM, an overall perspective of the degradation mechanisms and factors affecting the durability, as well as the strategies used to characterize it, may be found in the literature regarding EBR. For reference, Table 1 summarizes the studies dedicated to the bond durability of EBR carbon FRP-concrete systems under different exposure conditions and for various times of exposure. Most of the studies report high degradation ratios of bond strength and changes in the failure modes after the exposure to different environments in comparison with control specimens. Depending on the exposure conditions, time of exposure, type of test configuration and mainly the type 
Fernandes, P.; Sena-Cruz, J.; Xavier, J.; Silva, P.; Pereira, E.; Cruz, J.R. (2018) "Durability of bond in NSM CFRP-concrete systems under different environmental conditions. ” Composites Part B, 138: 19-34.

of adhesive used, reductions of up to $70 \%$ the bond strength after exposure with respect to its initial value can be obtained.

The comparison between the results reported in the literature for EBR and NSM techniques is not straightforward, if one considers that this comparison is strongly affected by variables actually considered in each study, such as the class of concrete, the type of FRP, characteristics/type of epoxy resin, the test configurations, the environmental conditions and time of exposure considered. Nevertheless, it seems reasonable to infer from the available results that the EBR FRP systems tend to be more vulnerable to ageing factors, presenting higher degradations ratios in comparison to NSM FRP systems.

The main objective of the experimental research reported in this paper is to contribute to the knowledge on the durability of bond of carbon fibre reinforced polymer (CFRP) laminate strips used as strengthening of RC elements according to the NSM technique. The environmental conditions included both the exposure to accelerated degradations laboratory-based conditions that mimic harsh environments, and real-life environments that are prevalent at the coast and interior regions of the Portugal, for an exposure time that ranged between four and twenty four months. The bond damage evolution was evaluated through direct pullout bond tests in specimens after different periods of exposure to different environmental conditions. The bond length, the groove geometry and the concrete strength class were considered as fixed parameters. The changes in the bond behaviour were investigated in terms of bond strength (pullout force), slip and failure mode. In order to evaluate the influence of each component of the NSM CFRP-concrete system on the global bond response, samples of concrete, epoxy adhesive and CFRP were used to assess the changes in the material mechanical properties over the time after being exposed to different environmental conditions. The most widely used in-situ non-destructive testing methods for bond monitoring in FRP-strengthened elements are the visual inspection and hammer tapping [11]. However, there are other methods that are being applied and developed, such as digital image correlation (DIC), infrared (IR) thermography [23-25] and X-ray tomography [26, 27]. Regarding the IR thermography method the applications are mostly focused on the qualitative assessment and the localization of the defects, due to resolution limitations of this technique. On the other hand, X-ray tomography is the conventional technique to study an internal structure with high resolution and allows to document the damage in depth, beyond the specimen's surface. However, it is not possible to use this technique to continuously document the damage evolution during the pullout test. In addition, X-ray tomography is expensive and time-consuming. Among these techniques, DIC has been selected as advanced and complementary measurement technique for monitoring the NSM pullout tests and contribute to assessing the bond damage evolution. 
Fernandes, P.; Sena-Cruz, J.; Xavier, J.; Silva, P.; Pereira, E.; Cruz, J.R. (2018) "Durability of bond in NSM CFRP-concrete systems under different environmental conditions." Composites Part B, 138: 19-34.

Given that the existence of durability studies of bond NSM FRP-concrete systems similar to the one presented in this paper is still scarce, it is considered as fundamental to assess the suitability of the proposed ageing tests protocols in order to include the greatest diversity of possible environmental exposure conditions. Thus, in this study a special effort was made to include the wide diversity of environmental exposure conditions that can have a relevant influence. These results are essential to support future investigations on analytical/numerical models to describe and simulate the durability of these systems.

\section{EXPERIMENTAL PROGRAM}

The experimental study reported herein was devised to characterize the durability of bond between concrete substrate and NSM CFRP strips when exposed to different environmental conditions. Post-ageing tests were carried out after exposing the specimens to different environmental conditions, including the mechanical characterization of the materials and of the bond behaviour of the NSM CFRP-concrete system. The following sections describe the experimental program, specimen's geometry and test configurations adopted to characterize the various materials (concrete, CFRP laminate and epoxy adhesive) and the bond behaviour.

\subsection{Description of the experimental program}

In order to assess the durability of the bond in the NSM CFRP-concrete system an experimental program composed by twenty three subseries of direct pullout tests (DPT) was carried out, where each subseries was composed by four specimens. Table 2 presents the environmental conditions and the corresponding specimen subseries included in the experimental program. The exposure time of the specimens ranged between four and twenty four months depending on the type of environmental exposure. After approximately one half of the time of exposure, for series TW, CW, WD, TCA and FT one half of the specimens was removed from the corresponding environmental exposure conditions and were monotonically tested up to failure, whereas the remaining specimens were kept exposed to the environmental conditions till the end. Reference series (non-aged specimens) were kept in laboratory environment and were also tested at the same time of aged specimens.

The environmental exposure conditions were divided into two groups:

1. Laboratory-based ageing conditions:

a. specimens kept in the laboratory environment at an average temperature of $20^{\circ} \mathrm{C}$ and relative humidity $(\mathrm{RH})$ of $56 \pm 10 \%$, being the minimum and maximum temperatures registered equal to, respectively, $9{ }^{\circ} \mathrm{C}$ and $33^{\circ} \mathrm{C}$, which correspond to the seasonal temperatures (series LE); 
Fernandes, P.; Sena-Cruz, J.; Xavier, J.; Silva, P.; Pereira, E.; Cruz, J.R. (2018) "Durability of bond in NSM CFRP-concrete systems under different environmental conditions." Composites Part B, 138: 19-34.

b. $\quad$ specimens immersed in tap water at an average temperature of $22{ }^{\circ} \mathrm{C}$, ranging between $17^{\circ} \mathrm{C}$ and $26^{\circ} \mathrm{C}$ (series TW);

c. specimens immersed in tap water with $3.5 \%$ concentration of $\mathrm{NaCl}$ at an average temperature of $22{ }^{\circ} \mathrm{C}$, ranging between $17^{\circ} \mathrm{C}$ and $26^{\circ} \mathrm{C}$ (series CW) - the standard ASTM D1141-98 [28] recommends $24.53 \mathrm{~g}$ of $\mathrm{NaCl}$ per litre of water, which represents a concentration of $2.453 \%$ of $\mathrm{NaCl}$ and, according to this standard, is representative of seawater, however a concentration of $3.5 \%$ was adopted instead, in order to promote accelerated degradation;

d. specimens exposed to wet-dry cycles in tap water with $3.5 \%$ concentration of $\mathrm{NaCl}$ at an average temperature of $22^{\circ} \mathrm{C}$ (series WD) - each wet-dry cycle consisted of full immersion for 3 days (wetting), followed by 4 days of drying;

e. specimens exposed to temperature cycles between $-15{ }^{\circ} \mathrm{C}$ and $+60{ }^{\circ} \mathrm{C}$ (series TCA) and between $+20{ }^{\circ} \mathrm{C}$ and $+80{ }^{\circ} \mathrm{C}$ (series TCB) had a complete cycle duration of 24 hours (h). The range of temperatures adopted considered the need to investigate the bond damage induced by temperature cycles when the maximum temperature remains below (series TCA) or exceeds (series TCB) the glass transition temperature of the epoxy adhesive. According to the dynamic mechanical analysis (DMA) performed by Firmo et al. [29] the $T_{g}$ of the epoxy used is in the range between $55^{\circ} \mathrm{C}$ and $62{ }^{\circ} \mathrm{C}$, depending on the chosen heating rate during the test. In the exposure condition TCA the imposed temperature cycle program was defined based on EN 13687-3:2002 standard [30], with a $12.5 \mathrm{~h}$ temperature plateau at $-15{ }^{\circ} \mathrm{C}$ and a $10 \mathrm{~h}$ temperature plateau at $+60{ }^{\circ} \mathrm{C}$. The almost linear transition between these two temperature plateaus took $1.5 \mathrm{~h}$. Despite of the RH was pre-set to a fixed value in the climatic chamber, a monotonic decrease from $55 \%$ to $20 \%$ was observed while the temperature was at $60{ }^{\circ} \mathrm{C}$, and a monotonic increase from $20 \%$ to $85 \%$ occurred while the temperature was at $-15^{\circ} \mathrm{C}$. The observed variation of RH occurred due to the technical limitations of the climatic chamber. In the case of the exposure condition TCB, two temperature plateaus were prescribed, at $+20{ }^{\circ} \mathrm{C}$ and at $+80{ }^{\circ} \mathrm{C}$. In both cases these two temperature levels were kept constant for $11.5 \mathrm{~h}$, and the almost linear transitions between the lower and the higher temperature plateaus took $0.5 \mathrm{~h}$. The RH ranged between $5 \%$ and $55 \%$ during the cycles of series TCB;

f. specimens exposed to freeze-thaw cycles (series FT) were subjected to a temperature of $-18{ }^{\circ} \mathrm{C}$ for $13 \mathrm{~h}$, and to a temperature of $+20{ }^{\circ} \mathrm{C}$ for $3 \mathrm{~h}$. The transition from the negative to the positive temperature plateau lasted for $5 \mathrm{~h}$, while the transition from the positive to the negative temperature 
Fernandes, P.; Sena-Cruz, J.; Xavier, J.; Silva, P.; Pereira, E.; Cruz, J.R. (2018) "Durability of bond in NSM CFRP-concrete systems under different environmental conditions." Composites Part B, 138: 19-34.

plateau took $3 \mathrm{~h}$. The complete FT cycle, with a duration of $24 \mathrm{~h}$, was defined based on CEN/TS 12390-9:2006 standard [31]. The specimens were kept fully immersed in water during the plateau of positive temperature exposure.

2. Real outdoor ageing conditions:

a. specimens subjected to wet-dry cycles in marine environment (series RA), e.g. exposed to airborne salt (tidal and spray zones) in a warm Mediterranean/dry-summer subtropical environment ("Port of Leixões" situated in the north of Portugal). The temperature and RH measurements registered by the existing data station at "Port of Leixões" over the time of exposure (from July 2013 to August 2015) are plotted in Figure 1a. The minimum and maximum temperatures registered over the time of exposure were $3.8^{\circ} \mathrm{C}$ and $36.6^{\circ} \mathrm{C}$, respectively;

b. specimens exposed to warm and temperate environment (series RB) in outdoor conditions on the roof of a building. For this purpose the city of Guimarães - Campus of Azurém at the University of Minho -, located in the north of Portugal was selected. The temperature and RH measurements registered by the data station located very close to the roof of the building are plotted over the time of exposure (from January 2013 to May 2015) in Figure 1b. The minimum and maximum temperatures registered were $-1.9^{\circ} \mathrm{C}$ and $40{ }^{\circ} \mathrm{C}$, respectively.

The detailed description about environmental conditions considered in this study can be found in [32]. The test series were identified using alphanumeric characters, where the first string specifies the environmental condition (LE, TW, CW, WD, TCA, TCB, FT, RA and RB) and the last string indicates the time of exposure, i.e. the number of days during which the series' specimens remained exposed to the environmental conditions (120, 180, 240, 480, and 720 days). For the case of the series TCA, TCB, FT, RA and RB, in addition to the aged series, corresponding reference $(\mathrm{R})$ series' specimens were also tested at the same time.

\subsection{Materials}

A single concrete batch was used to cast all the specimens: concrete blocks for the DPT, as well as concrete cylindrical and cubic specimens for the concrete mechanical characterization. The concrete mixture was composed by $765.3 \mathrm{~kg} / \mathrm{m}^{3}$ of coarse aggregate (maximum aggregate size of $12.5 \mathrm{~mm}$ ), $125.8 \mathrm{~kg} / \mathrm{m}^{3}$ of fine aggregate, 345.8 $\mathrm{kg} / \mathrm{m}^{3}$ of fine sand, $562.3 \mathrm{~kg} / \mathrm{m}^{3}$ of coarse sand, $212.5 \mathrm{~kg} / \mathrm{m}^{3}$ of cement 42.5 type II, $143 \mathrm{~kg} / \mathrm{m}^{3}$ of fly ash, $124 \mathrm{l} / \mathrm{m}^{3}$ of water, and $2.9 \mathrm{~kg} / \mathrm{m}^{3}$ of plasticizer (Chrysoplast 820 ). 
Fernandes, P.; Sena-Cruz, J.; Xavier, J.; Silva, P.; Pereira, E.; Cruz, J.R. (2018) "Durability of bond in NSM CFRP-concrete systems under different environmental conditions." Composites Part B, 138: 19-34.

The mechanical characterization of the concrete was carried out using five cylindrical concrete specimens with $150 \mathrm{~mm}$ of diameter and $300 \mathrm{~mm}$ height. The specimens were tested 28-days after casting in order to evaluate the elastic modulus and the compressive strength according to, respectively, LNEC E397-1993:1993 and NP EN 12390-3:2011 recommendations [33, 34]. Additionally, at the same age, three concrete cubic specimens of $150 \mathrm{~mm}$ of edge were also tested following the same standard [34]. The evolution of the compressive strength of the concrete was assessed over time, namely through compression tests performed on concrete cubic specimens at the same time as the direct pullout tests performed on aged specimens.

The CFRP laminate strips used in the present experimental work, with a cross-sectional area of $10 \times 1.4 \mathrm{~mm}^{2}$, and a trademark S\&P Laminates $C F K 150 / 2000$, were produced by $\mathrm{S} \& \mathrm{P}^{\circledR}$ Clever Reinforcement Company. This laminate is prefabricated by pultrusion, is composed of unidirectional carbon fibres agglutinated by an epoxy vinylester resin, has a smooth external surface and its colour is black. The tensile properties of the CFRP laminate strips were assessed according to ISO 527-5:2009 [35]. A total of 72 CFRP laminate specimens were tested, divided in 12 series of six specimens. The specimens' length was $250 \mathrm{~mm}$, and tabs of $50 \mathrm{~mm}$ length were glued to the edges to avoid premature failure of the specimen due to stress concentrations introduced by the loading equipment fixtures. To evaluate the elastic modulus, a clip gauge with $50 \mathrm{~mm}$ of gage length was mounted at the central region of each specimen. The elastic modulus was determined, according to ISO 527-5:2009, as the slope of the linear trend line of the stress-strain response between strain values of $0.05 \%$ and $0.25 \%$.

A two-component epoxy resin-based adhesive was used, with a trademark $S \& P$ Resin 220 epoxy adhesive ${ }^{\circledR}$, produced by the same supplier of CFRP laminates. This epoxy adhesive is a solvent-free, thixotropic, grey material that has been specially developed for bonding carbon fibre laminates to concrete substrates (S\&P laminates CFK). Epoxy dog-bone shaped specimens, according to geometry "type 1A" as defined by EN ISO 527-2:2012 [36], were tested in direct tension according the same standard [36], after being subjected to the environmental conditions previously described (see Table 2). Four batches were prepared to cast a total of 78 specimens, divided in 13 series of six specimens. A strain gauge (type: BFLA-5-3-3L by TML; measuring length: $5 \mathrm{~mm}$; gauge factor: $2.08 \pm 1 \%$ ) was installed at the top surface of each specimen, at mid-length, to measure its longitudinal strain. The elastic modulus was calculated according to EN ISO 527-1:2012 [37] as the slope of the secant line of the stress-strain response between $0.05 \%$ and $0.25 \%$ strain on the curve. Further details about the test procedures and the results obtained may be found elsewhere [32]. 
Fernandes, P.; Sena-Cruz, J.; Xavier, J.; Silva, P.; Pereira, E.; Cruz, J.R. (2018) "Durability of bond in NSM CFRP-concrete systems under different environmental conditions. ” Composites Part B, 138: 19-34.

\subsection{Pullout tests: specimen's geometry and test configuration}

Direct pullout tests (DPT) were carried out using concrete cubic blocks of $200 \mathrm{~mm}$ of edge, as shown in Figure 2. CFRP laminate strips $1.4 \mathrm{~mm}$ thick and $10 \mathrm{~mm}$ wide were embedded in these concrete blocks and inserted in $5 \mathrm{~mm}$ thick and $15 \mathrm{~mm}$ deep grooves performed at the surface of the concrete blocks.

The bond length adopted in the present work was obtained through a preliminary sequence of tests. The development (or effective) bond length is defined as the bonded length required to achieve the bond strength of a reinforcement at a critical section [38]. For this purpose, an experimental program composed of nine DPT tests was prepared. Bond lengths of 60, 80 and $100 \mathrm{~mm}$ were considered for assessing the development bond length. The age of the bond specimens at the date of testing was about five months. Figure 4 shows the influence of the bond length on the maximum pullout resistance. As shown the development length is around to $80 \mathrm{~mm}$, which is the minimum bond length which leads to the rupture of the FRP. In this context, a constant bond length of $60 \mathrm{~mm}$ filled with the epoxy adhesive was adopted, based on the following premises:

(i) the bond length must be large enough to be representative of the system and to make negligible the unavoidable end effects;

(ii) the failure of the FRP reinforcement during testing should be avoided.

The preparation of the strengthened specimens required several steps, mainly: (i) opening the grooves; (ii) cleaning the grooves and the CFRP laminates; (iii) filling the groove with epoxy adhesive and applying epoxy on the lateral surfaces of the laminate; (iv) introducing carefully the laminate into the centre of the groove; (v) level the surface. The application of the NSM CFRP strips at the surface of the concrete blocks was carried out at about 3 months after concrete casting, and 2 months after making the grooves. The epoxy samples were manufactured simultaneously to the bond specimens. These procedures were performed under laboratory conditions with an average temperature of about $25^{\circ} \mathrm{C}$ and $42 \%$ of $\mathrm{RH}$. After being strengthened, all the specimens (including materials samples) were kept in the laboratory environment before being moved to the corresponding environmental exposure conditions. The main tasks and the sequence of procedures performed during this work are shown in Figure 3. Detailed description about the specimen geometry, configuration of the DPT test, specimen preparation and ageing test procedures can be found elsewhere [32].

The pullout tests were performed by using a closed steel frame equipped with a servo-controlled loading equipment. A linear variable differential transducer, LVDT (range $\pm 2.5 \mathrm{~mm}$ and linearity error of $\pm 0.05 \%$ F.S.) was used to measure the slip at the loaded end, $s_{l}$. The applied load, $F$, was registered by a load cell placed between the grip and the actuator, with a static load carrying capacity of $200 \mathrm{kN}$ (linearity error of $\pm 0.05 \%$ F.S.). The 
Fernandes, P.; Sena-Cruz, J.; Xavier, J.; Silva, P.; Pereira, E.; Cruz, J.R. (2018) "Durability of bond in NSM CFRP-concrete systems under different environmental conditions. ” Composites Part B, 138: 19-34.

monotonic tests were performed under force control at a loading rate of $0.013 \mathrm{kN} / \mathrm{s}$ up to $10 \mathrm{kN}$, and then under displacement control by using the displacement measured by a LVDT positioned at the loaded end section as control variable, at a rate of $2 \mu \mathrm{m} / \mathrm{s}$.

The DPT tests were also monitored using Digital Image Correlation (DIC) technique. The ARAMIS DIC-2D v6.02 software by GOM was used in this work $[39,40]$. The measurement system was equipped with an 8-bit ChargedCoupled Device (CCD) Baumer Optronic FWX20 camera coupled with a Nikon AF Zoom-Nikkor 28-105mm f/3.5-4.5D IF lens. The adopted working distance (defined as the distance between the external face of the camera and the target surface) was $654 \mathrm{~mm}$ leading to a conversion factor of $0.05 \mathrm{~mm} /$ pixel. The lens aperture was set to f/11 for enhancing depth of field and avoiding diffraction effects (smallest apertures) during the test. Lighting intensity and shutter time were adjusted in order to obtain a uniform illumination, avoid pixel saturation and prevent motion blur in the images during exposure. The shutter time was set to $4.5 \mathrm{~ms}$. Images were recorded with an acquisition frequency of $0.1 \mathrm{~Hz}$, allowing the monitoring of the specimen's surface deformation during the entire test. A subset size of $15 \times 15$ pixels $^{2}$, a subset step of $13 \times 13$ pixels $^{2}$, and a strain gauge length of 5 subsets were selected. For this strain length, a strain resolution of around $0.0135 \%$ was obtained, which is still suitable for measuring the strains of the used materials. The DPT specimens monitored with DIC were prepared by applying a speckle pattern on the region of interest (ROI). Firstly, the surface of the ROI was previously smoothed by applying a thin layer of plaster (repair cementitious past), in order to fill the voids, and polished afterwards by using sandpaper with different grit sizes. Then, a thin coating of a white matt paint was applied, followed by a spread distribution of black dots using spray paint over a polished region of interest. In order to prove and clarify the obtained results with DIC method a single DPT test (RA720R_3) was carried out with a high resolution camera in order to visually document the cracks possibly forming during the loading. For this purpose, a single-lens reflex $($ SLR) camera with a full frame sensor $(24 \mathrm{~mm} \times 36 \mathrm{~mm})$ and $36 \mathrm{MP}$ coupled with a Nikon macro lens (1:1) with $105 \mathrm{~mm}$ of focal distance and f/2.8 of maximum aperture, was used. Taking to account the symmetry of the NSM CFRP-concrete specimen and the field of view of the high resolution camera, it was decided to monitor only half of the ROI, assuming that the behaviour of the specimen can be considered approximately symmetric with regard to the centreline of the loading. Furthermore, this configuration allowed to measure the crack length with respect to the longitudinal axis of the CFRP, as well as the area of influence (effective width of the NSM reinforcement that is mobilized during the test) on the NSM CFRP-concrete system. 
Fernandes, P.; Sena-Cruz, J.; Xavier, J.; Silva, P.; Pereira, E.; Cruz, J.R. (2018) "Durability of bond in NSM CFRP-concrete systems under different environmental conditions." Composites Part B, 138: 19-34.

\section{RESULTS AND DISCUSSION}

\subsection{Materials}

\subsubsection{Concrete}

The results obtained in the compression tests at 28-days of concrete age indicated: (i) an average compressive strength in cylinders, $f_{c m}$, of $36.0 \mathrm{MPa}$, with a coefficient of variation $(\mathrm{CoV})$ of $3.9 \%$; (ii) an average compressive strength in cubes, $f_{c m, \text { cube }}$, of $43.1 \mathrm{MPa}(\mathrm{CoV}=5.1 \%)$; and (iii) an average elastic modulus, $E_{c m}$, of $28.4 \mathrm{GPa}$ $(\mathrm{CoV}=5.8 \%)$. The evolution of the compressive strength in cylinders over the time for the specimens with or without ageing is shown in Figure 5a. These values are obtained by extrapolation of the cubic compressive strength over the time, based on a relation between compressive strength obtained from cylinder and cubic specimens at 28-days of concrete age. The ratio of strengths obtained is in agreement with Eurocode 2 [41]. As previously stated, it is important to highlight that the reference compression tests were performed at the same curing time of the aged cubic specimens exposed to different environmental conditions.

The results obtained for the compressive strength showed that the maximum compressive strength was achieved after approximately one year after casting (see Figure 5a). This result is explained by the considerable amount of fly ash added to the concrete composition (the fraction of fly ash was $40 \%$ of the total binder content). The fly ash has a delayed contribution for the maturation and strength gain in concrete, therefore after 28 -days of maturation the concrete compressive strength continues to increase significantly, at least until it reaches one year of age [42, 43].

Figure $5 \mathrm{~b}$ shows the compressive strength evolution for concrete specimens subjected to the distinct environmental conditions. In this Figure, the variation of concrete compressive strength was defined as the ratio $\left(f_{c m, S e r i e s}-f_{c m, L E}\right)$ I $f_{c m, L E}$, being $f_{c m, \text { Series }}$ the average value of the concrete compressive strength of the series to be analysed and $f_{c m, L E}$ the average concrete compressive strength, obtained by averaging the compressive test results of all the specimens of series LE tested between 370 and 1184 days after casting. In general, all the environmental conditions studied did not cause remarkable variations on the concrete compressive strength. The temperature cycles with temperatures ranging between $+20{ }^{\circ} \mathrm{C}$ and $+80{ }^{\circ} \mathrm{C}$ (TCB180) led to a maximum decrease on the compressive strength of about $15 \%$. Similar behaviour was also observed and reported by previous research works, see e.g. [44]. According to Bulletin No. 38 of $f i b$ [45] the chemical structure of the hardened cement paste does not change below $80{ }^{\circ} \mathrm{C}$; therefore, the change in strength may be attributed to changes in the van der Waals cohesive forces, porosity, surface energy or micro-cracking due to thermal incompatibility between aggregate particles and hardened cement paste. In general, a slight increase of the compressive strength (less than 8\%) was verified for 
Fernandes, P.; Sena-Cruz, J.; Xavier, J.; Silva, P.; Pereira, E.; Cruz, J.R. (2018) "Durability of bond in NSM CFRP-concrete systems under different environmental conditions. ” Composites Part B, 138: 19-34.

the specimens immersed in tap water (series TW240 and TW480), immersed in water with chlorides (series CW240 and CW480), exposed to wet/dry cycles in tap water with chlorides (series WD240) and freeze and thaw cycles (series FT240), excluding series WD480 that present an opposite trend. These small improvements may be related to the post-hydration of non-hydrated fly-ash and/or cement within the concrete [46-48]. The temperature cycles between $-15^{\circ} \mathrm{C}$ and $+60^{\circ} \mathrm{C}$ (TCA120 and TCA240) changed marginally the concrete strength.

\subsubsection{CFRP laminate}

The variation of the tensile strength, $f_{f u}$, and elastic modulus, $E_{f}$, of CFRP specimens when subjected to different environmental conditions are shown in Figure 6. The results show the average of results obtained from six tested samples for each environmental condition. In general, in each series reduced scatter of results were found, expressed by coefficients of variation $(\mathrm{CoV})$ of less than $3 \%$ for $f_{f u}$ and less than $5 \%$ for $E_{f}$, which are reasonable values considering the materials tested [49]. For all CFRP specimens, the failure modes showed very fast propagation of damage due to the progressive rupture of the individual fibres at mid-height of the specimen.

In general, the CFRP specimens seemed to have endured the ageing tests without great losses on their mechanical properties (see Figure 6). The results show a maximum decrease on the tensile strength of about $7 \%$ for the series CW480 and WD480 (when compared to the control series, LE0). The maximum reduction observed on the elastic modulus and on the ultimate strain were 2.6\% (series WD240) and 6\% (series CW480), respectively. The effects of temperature cycles and freeze-thaw cycles on the mechanical properties of CFRP were shown to be negligible. Previous studies which considered similar exposure environments, such as immersion in demineralised water and immersion in salt water at room temperature, elevated temperatures and freeze-thaw cycles, have reported similar results $[50,51]$

\subsubsection{Epoxy adhesive}

After being exposed to the environmental conditions, the specimens of epoxy adhesive were stored in a plastic hermetic box and kept in the climatic chamber at $20^{\circ} \mathrm{C}$ prior being tested, as detailed in Figure 3 . The main results in terms of the average tensile strength, $f_{a u}$, and elastic modulus, $E_{a}$, obtained from the tensile tests on epoxy adhesive aged and non-aged specimens are presented in Figure 7. The mechanical properties of the epoxy adhesive obtained in the specimens submitted to the different environmental conditions show different ratios of degradation or improvement in terms of the elastic modulus and tensile strength. These variations have been also observed with similar trends by other researchers, e.g. [52-56]. The mechanical properties obtained for both reference series 
Fernandes, P.; Sena-Cruz, J.; Xavier, J.; Silva, P.; Pereira, E.; Cruz, J.R. (2018) "Durability of bond in NSM CFRP-concrete systems under different environmental conditions." Composites Part B, 138: 19-34.

(LE0 and LE480) presented a slightly higher than expected dispersion of results. These differences can be related to the fact that the specimens have been made from different mixes of the epoxy resin, even though the same container was used and the same curing conditions were adopted [57, 58].

In general, a strong reduction on mechanical properties was observed for the series exposed to environments TW, CW, WD, FT (up to $47 \%$ and $38 \%$ for elastic modulus and tensile strength, respectively). These reductions of the average mechanical properties were explained by the existence of water in the exposure environments. Epoxy adhesives absorb water and, as a consequence, they suffer plasticization, increasing their volume and decreasing their mechanical properties, namely the stiffness, the tensile strength and the glass transition temperature [59, 60]. The water uptake was not assessed for epoxy adhesive used. However, according to the existing literature, epoxy adhesive maximum water uptake is about 3 to $4 \%$ and is reached approximately one year after immersion, e.g. [55].

On the other hand, significant increases on the mechanical properties of the epoxy adhesive (up to $33 \%$ and $58 \%$ for elastic modulus and tensile strength, respectively) were observed for the series exposed to the temperature cycles TCA (temperature cycles from $-15^{\circ} \mathrm{C}$ to $+60{ }^{\circ} \mathrm{C}$ ) and TCB (temperature cycles from $20{ }^{\circ} \mathrm{C}$ to $+80{ }^{\circ} \mathrm{C}$ ). These improvements on mechanical properties are due to a post-curing phase caused by the temperature cycles $[61,62]$. The post-curing process on this type of material occurs when temperatures higher than the ones experienced at the first curing are attained. Additional details about the results obtain with the epoxy adhesive can be found in [63].

\subsection{NSM CFRP-concrete system}

\subsubsection{Assessment by digital image correlation}

Digital Image Correlation method was used to document the evolution of the bond resistant mechanisms at the surface of the concrete elements where the NSM CFRP strips were installed. This method allows to derive the fullfield deformation over the whole region of interest consisting of concrete and epoxy adhesive over the ligament region. In regard to the NSM technique, since the FRP material is embedded in the concrete substrate (concrete cover), it is no possible to measure the strains directly in the CFRP laminate. Additionally, the imaging of the external surface of the ligament region and the subsequent extraction of the deformation fields in this region provide relevant overall information about the NSM system global behaviour. The experimental program including imaging and DIC entailed the monitoring of two specimens per series, in the following series: FT120, LE240, LE480, TW240, TW480, CW240, CW480, WD240 and WD480. Comparisons between aged and unaged 
Fernandes, P.; Sena-Cruz, J.; Xavier, J.; Silva, P.; Pereira, E.; Cruz, J.R. (2018) "Durability of bond in NSM CFRP-concrete systems under different environmental conditions. ” Composites Part B, 138: 19-34.

specimens were performed. No differences with significance were found. Thus, for the sake of simplicity, the overall discussion will be supported on specimen LE480_3. Figure 8 shows the region of interest (ROI) of $60 \times$ $45 \mathrm{~mm}^{2}$ used as the basis for performing the DIC analysis. This ROI was defined as a compromise between spatial resolution and accuracy, taking into account the bonded length of the specimens and the expected influence area due to the loading effects. Consequently, the analysis was focused on the surface deformations and strain fields obtained for concrete and epoxy adhesive along the bonded length for both directions $x$ and $y$ (see Figure 8), being $x$ the direction of the pullout force which is applied at the right hand side of the picture.

The typical pullout force-loaded end slip response $\left(F_{l}-s_{l}\right)$ obtained for the reference specimen LE480_3 is shown in Figure 9. Analysing the $F_{l}-s_{l}$ relationship, the following three branches can be distinguished:

(i) an initial almost linear branch that results from the chemical bond existing between the three materials: adhesive, concrete and CFRP;

(ii) after an initial short linear branch the response becomes nonlinear up to the peak load, justified by the nonlinear behaviour of the epoxy adhesive, as well as, by the chemical bond degradation at the concrete/adhesive and adhesive/CFRP interfaces - the debonding process begins mainly at the laminate/adhesive interface;

(iii) after the peak load, a post-peak descending branch is observed, characterized by a significant decay of the pullout force due to the further degradation of the bond mechanisms at the interfaces and probably due to adhesive cracking. After this phase the bond resistance is mainly governed by frictional forces at the adhesive/CFRP interface. When the debonding process starts near the loaded end section, the maximum shear stress regions move towards the free end section direction, while the frictional mechanisms are activated in the previous regions. Thus, the friction component also contributes to the bond resistance.

The evolution of maximum principal strains (tensile strains) over the ROI for different load levels of the pullout force obtained from the DIC measurements is also presented in Figure 9. The strains fields, obtained using DIC, are a physical evidence of the resisting mechanism reported by Sena-Cruz and Barros [64]. The maximum principal strain maps obtained reveal that diagonal compressive forces, or struts, are developed in the adhesive and then transferred to the concrete substrate, producing a "fish-spine" crack pattern.

The bond resisting mechanism of the NSM CFRP-concrete system is composed of two distinct resisting mechanisms which are active in different stages: firstly the adhesion mechanisms prevail $[65,66]$ through chemical bond/adhesion between materials (concrete/adhesive and adhesive/CFRP), which for the case of the pure 
Fernandes, P.; Sena-Cruz, J.; Xavier, J.; Silva, P.; Pereira, E.; Cruz, J.R. (2018) "Durability of bond in NSM CFRP-concrete systems under different environmental conditions. ” Composites Part B, 138: 19-34.

interfacial failure is critical for bars with a smoother surface [3]; in a second phase friction mechanisms at both the CFRP/adhesive and concrete/adhesive interfaces prevail, due to the degradation of the adhesion mechanisms at these interfaces. In fact, the smooth surface of CFRP strips is not sufficient to provide mechanical interlocking between the laminate and the adhesive and, since the rougher surface of the concrete leads to better bonding with the adhesive, the bond resistance relies primarily on chemical adhesion between the strip and the epoxy. The evolution of the cracking on the concrete surface can essentially be followed using the DIC technique, see strain maps in Figure 9. The first cracks appear near the loaded end section, and with the increase of the load, the cracks continue to form and develop towards the free end region.

In order to better understand the NSM CFRP-concrete bond resisting mechanism, two strain profiles were plotted in both directions. The locations of the longitudinal (P1) and transverse (P2) strains profiles in the ROI are illustrated in Figure 8. The longitudinal strains, $\varepsilon_{x}$ along both profiles are shown in Figure 10. Strain profiles at the post peak regime were not included since at this stage, in some specimens, detachment of concrete occurred over the ROI making the used DIC inaccurate. Analysing the evolution of $\varepsilon_{x}$ in profile P1, it can be observed that for load levels of up to $20 \mathrm{kN}$ the epoxy adhesive is in tension along the bond length (see Figure 10a). When the maximum pullout force $\left(F_{l \max }\right)$ is reached, approximately $60 \%$ of the bond length is in compression, being the remaining part of the bond length in tension. This behaviour can be explained by the debonding process. The debonding process starts in zones close to the loaded end and, with the increase of the pullout force, the maximum shear stresses moved towards the free end. As a consequence, diagonal compressive forces start to develop in the region of the adhesive which is closer to the loaded end, thus justifying that part of the adhesive along the bond length is in compression. From the analysis of the profile P2 (see Figure 10b) it is possible to conclude that the effective width of the NSM reinforcement at the level of the specimen surface is approximately $20 \mathrm{~mm}$ apart from the longitudinal axis of the CFRP. The effective width of the NSM reinforcement was defined as the width (transverse distance with respect to the NSM reinforcement longitudinal axis) along which the stresses are fully transferred from the FRP composite to the surrounding concrete, i.e. the area of concrete mobilized (plane view) during the test. After this length, the stress state at the concrete is not locally affected by the reinforcement. This information is very important to define a minimum value for the spacing between grooves, in order to avoid group effect between neighbour FRP reinforcements. The effective width of $20 \mathrm{~mm}$ is approximately $4 / 3$ of the groove's depth $\left(h_{\mathrm{g}}\right)$. Consequently, a minimum value for the spacing between grooves $\left(a_{\mathrm{g}}\right)$ of $2.7 h_{\mathrm{g}}+$ groove width is suggested. According to the literature [38, 67], the groove spacing for quadrangular FRP bar cross-section (rectangular or square) should be greater than twice the depth of the NSM groove $\left(a_{\mathrm{g}}>2 h_{\mathrm{g}}\right)$. These observations 
Fernandes, P.; Sena-Cruz, J.; Xavier, J.; Silva, P.; Pereira, E.; Cruz, J.R. (2018) "Durability of bond in NSM CFRP-concrete systems under different environmental conditions. ” Composites Part B, 138: 19-34.

confirm experimentally the three-dimensional nature of the debonding phenomenon $[68,69]$, which is commonly neglected in design procedures and in the discussion of experimental results [70]. However, the results presented are an initial step forward in the entire understanding of this phenomenon, and further studies are required to fully characterize the three-dimensional nature of the bond behaviour in NSM CFRP-concrete systems.

After testing all specimens were visually inspected. From this inspection, in general, no cracks were visible by naked eye. In fact, the cracks monitored and observed by DIC can be considered as micro-cracks because they are not easily identified without resourcing to optical tools. However, using a camera with higher resolution and the appropriate optics (see Section 2.3) these micro-cracks can be captured during the loading. The appearance and evolution of the observed cracks at the concrete surface and at different load levels are shown in Figure 11. The crack first identified was located close to the loaded end of the bond length for a pullout force of $15 \mathrm{kN}$. From this point onwards several other cracks have formed, at increasing load levels. The first cracks appeared near the loaded end and then the additional cracks were forming towards the free end section of the bond length, as already observed in DIC results. The crack tip opening displacement was measured at different load levels and the maximum value was $32 \mu \mathrm{m}$ at $F_{l, \max }=28.46 \mathrm{kN}$. These measurements were performed in images taken by the SLR camera, through the open source software ImageJ [71].

\subsubsection{Influence of environmental conditions}

The changes on the bond behaviour of the NSM CFRP-concrete system due to the exposure to different environmental conditions were analysed through the results of the post-ageing monotonic direct pullout tests, including visual inspection. Table 3 summarizes the main results obtained, which include the following parameters obtained: the maximum pullout force, $F_{l \max }$; the slip at the loaded end for $F_{l \max }, s_{l \max }$; the average bond strength at the CFRP-epoxy interface, $\tau_{\max }$, that is evaluated by the expression $F_{\operatorname{lmax}} /\left(P_{f} L_{b}\right)$, where $P_{f}\left(=2 \times w_{f}+2 \times t_{f}\right)$ is the perimeter of the CFRP cross-section in contact with the adhesive, being $w_{f}$ and $t_{f}$ the width and the thickness of the CFRP and $L_{b}$ is the bond length. Although in general the tangential stresses along the bond length are expected to be non-constant for different load levels, at $F_{\text {lmax }}$ the bond shear stresses along this length are approximately constant [72]. As a result, for $F_{\text {lmax }}$ and the range of dimensions adopted the effective length should be always approximately the same as the bond length $(60 \mathrm{~mm})$.

The typical average pullout force versus loaded end slip relationships $\left(F_{l}-s_{l}\right)$ obtained after the post-ageing tests with the specimens immersed in tap water and exposed to real environment A are shown in Figure 12. The corresponding average responses obtained for the reference series (LE480 and RA720R, respectively) were also 
Fernandes, P.; Sena-Cruz, J.; Xavier, J.; Silva, P.; Pereira, E.; Cruz, J.R. (2018) "Durability of bond in NSM CFRP-concrete systems under different environmental conditions. ” Composites Part B, 138: 19-34.

included. It should be remarked that each single average curve is the result of four tested specimens. The experimental responses in terms of $F_{l}-s_{l}$ for each single specimen can be found in [32]. By comparing the results obtained for aged and non-aged specimens (control specimens) tested at the same time, it can be observed that the overall shape of the $F_{l}-s_{l}$ responses is similar. However, it is possible to observe the slight decrease of the bond stiffness, which should likely be due to the reduction of the adhesion strength at the CFRP/adhesive interface, which results in a slight reduction of the maximum pullout force (see Figure 12b).

The evolution in time of the maximum pullout force of the reference series (LE, TCA120R, TCA240R, TCB180R, FT120R, FT240R, RA720R and RB720R) is presented in Figure 13. Some scatter is found in the results which is typical to this type of test e.g. [73, 74], which resulted for $F_{\text {lmax }}$ in a maximum coefficient of variation $(\mathrm{CoV})$ of $6.8 \%$ (see Table 3). It can be observed that the maximum pullout force of the control specimens stabilises approximately nine months after installing the NSM CFRP strips. Between 9 months and 3 years of age an average value of $F_{l \max }$ equal to $27.9 \mathrm{kN}$ is obtained. Moreover, for $86 \%$ of the tested reference specimens the main failure mode observed was pure debonding at the interface adhesive/laminate. The age after which the $F_{\text {lmax }}$ value may be considered as stable coincided with the stabilization of both the mechanical properties of concrete and the adhesion properties between materials. In fact, the change of the average pullout force obtained in the subseries LE0 of series LE, about six months after installing the NSM CFRP strips, is relatively lower (13\% in terms of average values) than the remaining series. This fact can be justified by the slight increase of the compressive strength of concrete (up to 5\%) and the improvement of the adhesion properties between materials along the time which was observed for all series with the exception of LE0.

The changes in the maximum pullout force due to the effect of the different environmental conditions are presented in Figure 14. These effects are expressed in terms of the variation of the mean values of $F_{\text {lmax }}$ obtained for the aged series with respect to the corresponding control series, tested at the same age. Four major observations can be pointed out:

(i) the maximum decrease on $F_{\text {lmax }}$ was registered for the real ageing conditions/environments RA and RB;

(ii) temperature cycles between $-15^{\circ} \mathrm{C}$ and $+60{ }^{\circ} \mathrm{C}$ resulted in the improvement of the bond behaviour;

(iii) the effect of the exposure time is clearly revealed by the degradation of the bond properties, being greater on the specimens that aged for longer periods;

(iv) the significant decrease of the tensile strength and elastic modulus of the epoxy resin did not have correspondence on the global bond behaviour of the NSM CFRP-concrete system, as shown in Figure 15. 
Fernandes, P.; Sena-Cruz, J.; Xavier, J.; Silva, P.; Pereira, E.; Cruz, J.R. (2018) "Durability of bond in NSM CFRP-concrete systems under different environmental conditions." Composites Part B, 138: 19-34.

In general, the observed changes in the mechanical properties of the epoxy adhesive, namely tensile strength and elastic modulus, do not have a directly quantifiable effect on the bond resistance of the NSM CFRP-concrete system. This may be due to the following reasons:

- The characterization of the mechanical behaviour of the epoxy is restricted to the tensile strength and elastic modulus; probably these may not be sufficient to fully characterize the epoxy behaviour in the context of the loading process in NSM CFRP-concrete system, particularly when shear or adhesive failures are concerned. Up to the peak load, the bond resisting mechanism is governed essentially by the chemical adhesion between materials, and although some degradation of the mechanical properties of the epoxy resin may exist (in a context where the other materials' degradation may be considered as marginal), it continues to be sufficiently high to ensure the bond;

- The maximum pullout force is limited by the type of failure mode. Since in most of the cases the failure occurs by debonding at adhesive/laminate interface, it means that the weakest component is the bond at adhesive/laminate interface (adhesion strength). Thus, the tensile strength of the epoxy adhesive is not directly comparable with adhesion strength at the interface between adhesive and laminate;

- The boundary conditions during ageing in the direct pullout specimens are different from the ones adopted in tensile tests to characterize the epoxy resin. For the case of the direct pullout specimens, the interface where the failure occurs (adhesive/laminate interface) is more protected from the environmental conditions, while the epoxy samples are directly exposed to these conditions.

The changes in the $F_{\text {lmax }}$ due to the effects of tap water immersion (TW), water with chlorides immersion (CW) and wet/dry cycles in tap water with chlorides (WD) were shown to be negligible (e.g. a decrease of $1.4 \%$ for the series WD480 and an increase of $4.9 \%$ for the series CW240). These small variations are in the range of the CoVs found for DPT tests for all environmental conditions $(0.5 \%$ to $6.8 \%)$. These results seem to indicate that the NSM CFRP system is not significantly vulnerable to these environmental conditions, considering the exposure times adopted.

For the case of series TCA120 and TCA240, the effect produced by the temperature cycles with temperatures ranging between $-15{ }^{\circ} \mathrm{C}$ and $+60{ }^{\circ} \mathrm{C}$ resulted in the improvement of the bond properties, with higher values obtained for $F_{l \max }, \tau_{\max }$ and $s_{l \max }$, when compared to the reference specimens. The maximum increase of $F_{l \max }$ was $8 \%$ after 240 days of ageing, which is in line with the improvement observed in the mechanical properties of the adhesive after being subjected to the same temperature cycles (see Section 3.1.3). However, despite a significant increase in mechanical properties of the epoxy adhesive (up to $31 \%$ and $15 \%$ in tensile strength and elastic 
Fernandes, P.; Sena-Cruz, J.; Xavier, J.; Silva, P.; Pereira, E.; Cruz, J.R. (2018) "Durability of bond in NSM CFRP-concrete systems under different environmental conditions. ” Composites Part B, 138: 19-34.

modulus, respectively), the influence on NSM CFRP-concrete system was much lower. Thus, the slight increase on the $F_{\operatorname{lmax}}$ observed for series TCA240 is justified by the improvement of the chemical adhesion between the CFRP laminate and the epoxy, mostly as a result of the improvement on mechanical properties of the epoxy itself. As a consequence, also higher friction resistance is expected. The failure mode was still governed by debonding at adhesive/laminate interface, comparing to the reference series (TCA240R), meaning that the weakest component of the system continues to be the adhesive strength at adhesive/laminate interface. As a result, the improvement on the mechanical properties of the epoxy is not fully translated in an equivalent improvement of the bond mechanisms.

For the specimens exposed to temperature cycles during 180 days, with temperatures ranging from $+20{ }^{\circ} \mathrm{C}$ and $+80{ }^{\circ} \mathrm{C}$ (series TCB 180 ), the variation of the $F_{\text {lmax }}$ was negligible. Therefore in this case the temperature cycles did not change the bond behaviour of the system, despite the significant improvement of the tensile properties of the epoxy. This result is not consistent with the results obtained for the $F_{l \max }$ of series TCA120 and TCA240. In fact, for the series TCB180 it was expected a slight increase in $F_{\text {lmax }}$, taking to account the range of the temperatures applied and the results obtained after the epoxy tensile testing. However, at the same time a reduction of about $15 \%$ on concrete compressive strength was observed. Therefore, probably for series TCB180 the reduction of the compressive strength of concrete in time was somewhat balanced by the improvements on mechanical properties of the epoxy adhesive.

Regarding the series FT, the ageing effect produced by the freeze and thaw cycles on the maximum pullout force is practically negligible, leading to a slight increase of $7 \%$ of $F_{\operatorname{lmax}}$ for the series FT120 and a small reduction (about $4.8 \%$ ) for series FT240 (see Figure 14.). In the first case, the slight increase can be justified by the results obtained in the corresponding reference series (FT120R), which showed lower resistance in comparison to the average of all $F_{\operatorname{lmax}}$ values obtained from all reference series (see Figure 13 and Table 3). Despite the tensile strength of epoxy the adhesive has decreased (approximately 17\%) the $F_{\text {lmax }}$ of the system CFRP-adhesive-concrete was not significantly affected by freeze-thaw cycles. However, a change on the failure mode from debonding at the CFRP/adhesive interface to cohesive failure on concrete was observed for the specimens subjected to 120 freeze-thaw cycles (series FT120) in comparison to control series (FT120R). For the specimens subjected to 240 freeze-thaw cycles (series FT240) the failure mode changed from debonding at the CFRP/adhesive interface to debonding failure at the adhesive/concrete interface, in comparison to control series (FT240R). Detailed explanation about the changes in the failure modes are presented in the next section. 
Fernandes, P.; Sena-Cruz, J.; Xavier, J.; Silva, P.; Pereira, E.; Cruz, J.R. (2018) "Durability of bond in NSM CFRP-concrete systems under different environmental conditions. ” Composites Part B, 138: 19-34.

Regarding to the real environments (RA and $\mathrm{RB}$ ), the maximum pullout force decreased $11.5 \%$ and $11.6 \%$ for the specimens submitted to wet-dry cycles in marine environment (series RA720) and outdoor environment (series RB720), respectively (see Figure 14). In fact, the effect of real exposure conditions has shown to be more aggressive than laboratory ageing conditions. In both real environments, the specimens were directly exposed to ultraviolet (UV) radiations. According to the literature the effect of UV radiation exposure on epoxy resin/polymer matrix could lead to the decrease of mechanical properties, and changes on physical properties and chemical structure that results in material degradation [75, 76]. Ferdous et al. [76] studied the effect of UV radiations exposure on the physical properties of epoxy resin based polymer matrix. The epoxy specimens were subjected to 2000 hours of UV radiation by Xenon 2200 watt air cooled lamp in the sunset XLS chamber. The results have shown that the maximum depth affected by UV exposure was $4.5 \mathrm{~mm}$ for epoxy resin containing $20 \%$ of filler. Consequently, these changes in physical and mechanical properties can reflect a loss of adhesion strength at the interface between adhesive and laminate of the present study. However, further research is needed to confirm and support the explanations above described.

Comparing all the environmental conditions, it becomes clear that the real ageing conditions induced higher degradation ratios on the global behaviour of the NSM system, see Figure 14. Furthermore, the effect of the exposure time also contributed significantly to the degradation of the bond properties, showing the specimens that aged for longer periods the higher degradations, as it was the case of the specimens subjected to real environments. Three different types of failure modes were observed in the specimens, as follows: (i) debonding at the interface FRP/adhesive (I-FA); (ii) debonding at the interface adhesive/concrete (I-AC); and (iii) cohesive shear debonding in concrete (C-C), as shown in Figure 16. Besides the three main failure modes above described, some specimens also included one (or more) of the following damages: concrete splitting (CS), concrete cracking (CC), and adhesive cracking (AC). Table 3 also provides information about the failure mode identified during the experiments.

The types of failure modes observed in each series are included in Table 3. As this table shows, the prevailing failure mode was the debonding at the interface CRFP/adhesive (I-FA), except for the specimens exposed to freezethaw cycles. In fact, the effectiveness of NSM strengthening technique critically depends on the superficial concrete resistance [3], which is normally the most degraded concrete part in the structure due to its greater exposure to environment conditions. Thus, the changes in the failure mode of the specimens exposed to freezethaw cycles can be justified by: (i) the reduction on the mechanical properties of the concrete cover substrate, although this reduction was not observed in concrete mechanical characterization through compression tests; 
Fernandes, P.; Sena-Cruz, J.; Xavier, J.; Silva, P.; Pereira, E.; Cruz, J.R. (2018) "Durability of bond in NSM CFRP-concrete systems under different environmental conditions." Composites Part B, 138: 19-34.

(ii) the decrease of the tensile strength of the adhesive after the exposure to the FT cycles; (iii) the deterioration of the adhesion between the epoxy adhesive and the concrete. As a consequence, cohesive shear failure on concrete (C-C) occurred in all the specimens exposed to 120 freeze-thaw cycles (FT120 series), confirming the low mechanical properties of superficial concrete (see Figure 16e). Furthermore, by increasing the number of FT cycles from 120 to 240, the specimens failed by debonding at the interface adhesive/concrete (FT240 series), as shown in Figure 16f.

As stated in the previous point (i), the compressive tests carried out using specimens exposed to similar freezethaw conditions may have led to an overestimation of the compressive strength of the concrete volume involved in the DPT tests, since the concrete at the surface is more prone to higher and faster deterioration due to exposure conditions.

In general, debonding failure at the CRFP/adhesive interface occurred without visible cracking in the concrete and/or in adhesive by naked eye (see Figures 16a and 16b). However, through a careful analysis using a high resolution camera, cracking of the epoxy cover and of the concrete surface were observed, as reported in Section 3.2.1. Additionally, in some specimens, besides the debonding failure at the interface CRFP/adhesive, concrete cracking or concrete splitting were also observed (see Figures 16c and 16d). The concrete splitting is characterized by a large area of detached concrete surrounding the bonded region. Cohesive failure within the concrete $(\mathrm{C}-\mathrm{C})$ depends on the degree of transverse confinement and on the mechanical properties of concrete [67]. Splitting may be caused when the concrete surrounding the reinforcement becomes the weakest material due to the environmental conditions (see Figure 16e).

\subsubsection{NSM versus EBR CFRP-concrete systems}

The results available in the literature for EBR CFRP-concrete systems have in general shown higher degradations ratios in comparison to the ones presented in this work using NSM CFRP systems. Despite the difficulty in performing a direct comparison, some aspects can be evidenced: (i) in terms of effect of moisture exposure, the results have shown significant degradation of bond strength for EBR (up to $68 \%$ when considering the reduction of the strength), whereas in the case of NSM systems a marginal degradation was registered (of about 1.4\%); (ii) for freeze-thaw exposure conditions the bond strength reduction of 25\% and 5\% were observed for EBR and NSM systems, respectively; (iii) on the other hand, for real environments (outdoor exposure) similar degradation ratios were obtained (15\% and 12\% for EBR and NSM systems, respectively). In order to confirm these observed trends, 
Fernandes, P.; Sena-Cruz, J.; Xavier, J.; Silva, P.; Pereira, E.; Cruz, J.R. (2018) "Durability of bond in NSM CFRP-concrete systems under different environmental conditions." Composites Part B, 138: 19-34.

further research involving both FRP systems (NSM and EBR) is necessary to complement the comparison of the durability performance between NSM and EBR systems.

\section{CONCLUSIONS}

This paper presented an experimental investigation for evaluating the durability of bond behaviour of NSM CFRPconcrete systems under different environmental conditions. For this purpose, concrete elements with embedded NSM CFRP strips were subjected to accelerated ageing tests at laboratory and tests in real outdoor environmental conditions. The main conclusions of the study can be summarized as follows:

1. In general, a slight increase on compressive strength of concrete (less than $8 \%$ ) was verified for the concrete samples submerged in tap water, in water with chlorides, subjected to wet/dry cycles and subjected to freeze and thaw cycles. This small increase on compressive strength of concrete may be related with the posthydration of non-hydrated fly-ash and/or cement within the concrete. The ageing effect produced by the temperature cycles with temperatures ranging between $+20^{\circ} \mathrm{C}$ and $+80{ }^{\circ} \mathrm{C}$ led to a maximum decrease of $15 \%$ of the compressive strength of concrete.

2. In general, the CFRP specimens presented small reductions of the tensile properties, with a maximum decrease of the tensile strength of about 7\% for the series CW480 and WD480 and a maximum reduction on the elastic modulus of about $3 \%$ for the series WD240. Thus, the CFRP material has shown very low vulnerability to the aggressive environments studied.

3. From the tensile tests performed on epoxy specimens, an increase of up to $58 \%$ and $33 \%$ on the ultimate tensile strength and elastic modulus were observed, respectively, for the series subjected to temperature cycles between $-15{ }^{\circ} \mathrm{C}$ and $+60{ }^{\circ} \mathrm{C}$ and between $+20{ }^{\circ} \mathrm{C}$ and $+80{ }^{\circ} \mathrm{C}$. A post-curing phase occurred in the epoxy due to the temperatures imposed in temperature cycles. A generalized decrease on the ultimate tensile strength and elastic modulus for series TW, CW and WD up to 38\% and 47\%, respectively, was observed. These reductions were likely due to water absorption (water uptake) by the epoxy during time.

4. The strain fields, determined with the DIC procedure, allowed to trace the resisting mechanism developed in the concrete surrounding the NSM CFRP application. These results revealed that the diagonal compressive forces (struts) are developed in the adhesive and then transferred to the surrounding concrete, producing a "fish-spine" crack pattern.

5. Taking into account the premises adopted in the present study, DIC results allowed to conclude that the influence area of the NSM CFRP-concrete bonded region extends for approximately $20 \mathrm{~mm}$ in the transverse 
Fernandes, P.; Sena-Cruz, J.; Xavier, J.; Silva, P.; Pereira, E.; Cruz, J.R. (2018) "Durability of bond in NSM CFRP-concrete systems under different environmental conditions." Composites Part B, 138: 19-34.

direction to each side of the CFRP laminate. This value is approximately $4 / 3$ of the groove's depth $\left(h_{\mathrm{g}}\right)$. Consequently, in order to avoid group effect between consecutive FRP reinforcements, the groove spacing $\left(a_{\mathrm{g}}\right)$ should be higher than $2.7 h_{\mathrm{g}}+$ groove width, for current cases.

6. In general, the results obtained from the durability tests conducted have shown that the effects of environmental conditions imposed, which may be considered as quite severe, did not result in significant damage on NSM CFRP-concrete system. The maximum decrease of about $12 \%$ on bond strength occurred under real outdoor environments (RA and $\mathrm{RB}$ ). Conversely, a maximum increase of $8 \%$ on bond strength was observed on bond specimens exposed to the temperature cycles between $-15^{\circ} \mathrm{C}$ and $+60{ }^{\circ} \mathrm{C}$.

7. The changes in the bond strength of the NSM CFRP-concrete system due to the effects of immersion in tap water (TW), immersion in water with chlorides (CW) and wet/dry cycles in tap water with chlorides (WD) were negligible (with a maximum reduction of $1.4 \%$ for the series WD480 and a maximum increase of $4.9 \%$ for the series CW240).

8. The predominant failure mode on bond pullout tests occurred by debonding at the interface CRFP/adhesive, except for the specimens exposed to freeze-thaw cycles.

9. The bond strength of the NSM CFRP-concrete system was not affected by freeze-thaw cycles. However, a change on the failure mode from debonding at the CFRP/adhesive interface to cohesive failure on concrete and to debonding failure at the interface adhesive/concrete was observed in the specimens subjected to 120 and 240 freeze-thaw cycles, respectively.

10. The strong reduction on the tensile stiffness and strength of the epoxy adhesive cannot be directly correlated with the global behaviour of the NSM CFRP-concrete system, since the variations of the mechanical properties observed in both types of specimens were not proportional.

11. The geometries of the specimens and the exposure conditions studied, as well as the reinforcement ratios adopted, have been devised having in mind their representativeness and their resemblance to common strengthening scenarios, therefore the conclusions are reasonably general. However, considering that the durability studies on NSM CFRP-concrete systems are still scarce, further studies with a significant ageing time (e.g. 10 years) are necessary to confirm these conclusions and to complement the collected data.

Finally, a comparison between the durability of studied NSM CFRP system and results available in the literature mostly for EBR CFRP-concrete systems have been carried out, since the number of studies reported using NSM are still limited. Although a direct comparison between the two systems is not straightforward, in general NSM CFRP systems seem to be more durable than the counterpart EBR CFRP systems. 
Fernandes, P.; Sena-Cruz, J.; Xavier, J.; Silva, P.; Pereira, E.; Cruz, J.R. (2018) "Durability of bond in NSM CFRP-concrete systems under different environmental conditions." Composites Part B, 138: 19-34.

\section{ACKNOWLEDGEMENTS}

This work is supported by FEDER funds through the Operational Program for Competitiveness Factors COMPETE and National Funds through FCT - Portuguese Foundation for Science and Technology under the projects CutInDur FCOMP-01-0124-FEDER-014811 (PTDC/ECM/112396/2009), FRPLongDur POCI-01-0145FEDER-016900 (PTDC/ECM-EST/1282/2014) and partly financed by the project POCI-01-0145-FEDER007633. The authors also like to thank all the companies that have been involved supporting and contributing for the development of this study, mainly: S\&P Clever Reinforcement Ibérica Lda., Artecanter - Indústria de Transformação de Granitos, Lda., Vialam - Indústrias Metalúrgicas e Metalomecânicas, Lda. The first and fourth authors also acknowledge the grants SFRH/BD/80338/2011 and SFRH/BD/89768/2012, respectively, provided by FCT. 
Fernandes, P.; Sena-Cruz, J.; Xavier, J.; Silva, P.; Pereira, E.; Cruz, J.R. (2018) "Durability of bond in NSM CFRP-concrete systems under different environmental conditions." Composites Part B, 138: 19-34.

\section{REFERENCES}

[1] Sena-Cruz J, Barros J, Bianco V, Bilotta A, Bournas D, Ceroni F, et al. NSM Systems. Design Procedures for the Use of Composites in Strengthening of Reinforced Concrete Structures: State-of-theArt Report 19 of the RILEM Technical Committee 234-DUC, C. Pellegrino and J. Sena-Cruz (eds.), 303-348.; 2015.

[2] Zhang SS, Yu T, Chen GM. Reinforced concrete beams strengthened in flexure with near-surface mounted (NSM) CFRP strips: Current status and research needs. Composites Part B: Engineering. 2017;131:30-42.

[3] De Lorenzis L, Teng JG. Near-surface mounted FRP reinforcement: An emerging technique for strengthening structures. Composites Part B: Engineering. 2007;38(2):119-43.

[4] Karbhari VM, Chin JH, D., Benmokrane B, Juska T, Morgan R, Lesko J, et al. Durability Gap Analysis for Fiber-Reinforced Polymer Composites in Civil Infrastructure. Journal of Composites in Construction, ASCE, 7:3 (2003) 238-247. 2003.

[5] Liao K, Schultheisz CR, Hunston DL, Brinson LC. Long-term durability of fiber reinforced polymermatrix composite materials for infrastructure applications: a review. Journal of Advanced Materials. 1998;30(4):3-40.

[6] ISIS. ISIS Canada Educational Module No. 8: Durability of FRP Composites for Construction. Prepared by ISIS Education Committee; 2006.

[7] Al-Mahmoud F, Mechling J-M, Shaban M. Bond strength of different strengthening systems Concrete elements under freeze-thaw cycles and salt water immersion exposure. Construction and Building Materials. 2014;70:399-409.

[8] Emara M, Torres L, Baena M, Barris C, Moawad M. Effect of sustained loading and environmental conditions on the creep behavior of an epoxy adhesive for concrete structures strengthened with CFRP laminates. Composites Part B: Engineering. 2017;129:88-96.

[9] Karbhari VM. Durability of composites for civil structural applications. Washington, DC: CRC Press; 2007.

[10] Benmokrane B, Ali AH, Mohamed HM, ElSafty A, Manalo A. Laboratory assessment and durability performance of vinyl-ester, polyester, and epoxy glass-FRP bars for concrete structures. Composites Part B: Engineering. 2017;114(Supplement C):163-74.

[11] Ghiassi B. Durability analysis of bond between composite materials and masonry substrates [PhD thesis]. Guimarães: University of Minho; 2013.

[12] Palmieri A, Matthys S, Taerwe L. Influence of High Temperature on Bond between NSM FRP Bars/Strips and Concrete. ACI Special Publication. 2011;275:1-12.

[13] Yu B, Kodur VKR. Effect of high temperature on bond strength of near-surface mounted FRP reinforcement. Composite Structures. 2014;110:88-97.

[14] Firmo J, Correia J, Pitta D, Tiago C, Arruda M. Bond Behavior between Near-Surface-Mounted CFRP Strips and Concrete at High Temperatures. Journal of Composites for Construction. 2014;19(4):04014071.

[15] Abdul Rahman N, Yail JK. An Experimental Investigation into the Residual Bond of NSM Composite Strips for Concrete at Elevated Temperatures. ACI Special Publication. 2014;298: 1-16.

[16] Burke PJ, Bisby LA, Green MF. Effects of elevated temperature on near surface mounted and externally bonded FRP strengthening systems for concrete. Cement and Concrete Composites. 2013;35(1):190-9.

[17] Garzón-Roca J, Sena-Cruz JM, Fernandes P, Xavier J. Effect of wet-dry cycles on the bond behaviour of concrete elements strengthened with NSM CFRP laminate strips. Composite Structures. 2015; 132:331-40.

[18] Wan B, Petrou MF, Harries KA. The effect of the presence of water on the durability of bond between CFRP and concrete. Journal of Reinforced Plastics and Composites. 2006;25(8):875-90.

[19] Correia L, Sena-Cruz J, Michels J, França P, Pereira E, Escusa G. Durability of RC slabs strengthened with prestressed CFRP laminate strips under different environmental and loading conditions. Composites Part B: Engineering. 2017;125:71-88.

[20] Kashi A, Ramezanianpour AA, Moodi F. Durability evaluation of retrofitted corroded reinforced concrete columns with FRP sheets in marine environmental conditions. Construction and Building Materials. 2017;151(Supplement C):520-33. 
[21] Triantafyllou GG, Rousakis TC, Karabinis AI. Effect of patch repair and strengthening with EBR and NSM CFRP laminates for RC beams with low, medium and heavy corrosion. Composites Part B: Engineering. 2018;133(Supplement C):101-11.

[22] Aydin H, Gravina RJ, Visintin P. A partial-interaction approach for extracting FRP-to-concrete bond characteristics from environmentally loaded flexural tests. Composites Part B: Engineering. 2018;132(Supplement C):214-28.

[23] Lai WL, Kou SC, Poon CS, Tsang WF, Ng SP, Hung YY. Characterization of Flaws Embedded in Externally Bonded CFRP on Concrete Beams by Infrared Thermography and Shearography. J Nondestruct Eval. 2009;28(1):27-35.

[24] Lai WL, Kou SC, Poon CS, Tsang WF, Lai CC. Characterization of the deterioration of externally bonded CFRP-concrete composites using quantitative infrared thermography. Cement and Concrete Composites. 2010;32(9):740-6.

[25] Tashan J, Al-mahaidi R. Investigation of the parameters that influence the accuracy of bond defect detection in CFRP bonded specimens using IR thermography. Composite Structures. 2012;94(2):51931.

[26] Goidescu C, Welemane H, Garnier C, Fazzini M, Brault R, Péronnet E, et al. Damage investigation in CFRP composites using full-field measurement techniques: Combination of digital image stereocorrelation, infrared thermography and X-ray tomography. Composites Part B: Engineering. 2013;48:95-105.

[27] Bull DJ, Spearing SM, Sinclair I, Helfen L. Three-dimensional assessment of low velocity impact damage in particle toughened composite laminates using micro-focus X-ray computed tomography and synchrotron radiation laminography. Composites Part A: Applied Science and Manufacturing. 2013;52:62-9.

[28] ASTM. Standard practice for the preparation of substitute ocean water. D1141-98. Annual Book of ASTM Standards, Volume: 15.05: American Society for Testing and Materials; 2003.

[29] Firmo JP, Correia JR, França P. Fire behaviour of reinforced concrete beams strengthened with CFRP laminates: Protection systems with insulation of the anchorage zones. Composites Part B: Engineering. 2012;43:1545-56.

[30] CEN. Products and systems for the protection and repair of concrete structures - Test methods Determination of thermal compatibility - Part 3:Thermal cycling without de-icing salt impact. EN 13687-3. Brussels, Belgium: European Committee for Standardization; 2002.

[31] CEN. Testing hardened concrete - Part 9: Freeze-thaw resistance - Scaling. TS 12390-9. Brussels, Belgium: European Committee for Standardization; 2006.

[32] Fernandes P. Bond behaviour of NSM CFRP-concrete systems: durability and quality control [PhD thesis]. Guimarães, Portugal: University of Minho; 2016.

[33] LNEC. Concrete - Determination of the elasticity young modulus under compression. E397-1993: Portuguese specification from LNEC; 1993.

[34] NP. Testing hardened concrete. Part 3: Compressive strength of test specimens. EN 12390-3. Caparica: Instituto Português da Qualidade (IPQ); 2011.

[35] ISO. Plastics - Determination of tensile properties - Part 5: Test conditions for unidirectional fibrereinforced plastic composites. 527-5. Genève, Switzerland: International Organization for Standardization; 2009. p. 11.

[36] ISO. Plastics - Determination of tensile properties - Part 2: Test conditions for moulding and extrusion plastics. 527-2. Genève, Switzerland: International Organization for Standardization; 2012. p. 5.

[37] ISO. Plastics - Determination of tensile properties - Part 1: General principles. 527-1. Genève, Switzerland: International Organization for Standardization; 2012. p. 13

[38] ACI. Guide for the Design and Construction of Externally Bonded FRP Systems for Strengthening Concrete Structures. 4402R-08. Farmington Hills, MI, USA: Report by ACI Committee 440, American Concrete Institute; 2008. p. 80.

[39] ARAMIS. Commercial software - v6.0.2-6. 2009. GOM (www.gom.com).

[40] Xavier J, de Jesus AMP, Morais JJL, Pinto JMT. Stereovision measurements on evaluating the modulus of elasticity of wood by compression tests parallel to the grain. Construction and Building Materials. 2012;26(1):207-15. 
[41] CEN. Eurocode 2: Design of concrete structures - Part 1-1: General rules and rules for buildings. EN 1992-1-1. Brussels, Belgium: European Committee for Standardization; 2004.

[42] ACI. Use of Fly Ash in Concrete. ACI 2322R-03. Farmington Hills, MI, USA: Report by ACI Committee 232, American Concrete Institute; 1996. p. 41.

[43] Lane RO, Best JF. Properties and use of fly ash in Portland cement concrete. Concrete International: Design \& Construction. 1982;4(7):81-92.

[44] Chowdhury SH. Effect of elevated temperature on mechanical properties of high strength concrete. In: Proceedings of 23rd Australasian Conference on the Mechanics of Structures and Materials (ACMSM23). Byron Bay, Australia, Conference 9-12 December, Conference 2014. p. 1077-82 pp.

[45] FIB. Fire design of concrete structures - materials, structures and modelling. Bulletin no. 38, The International Federation for Structural Concrete (FIB), State-of-art report prepared by Working Party 4.3-1, Lausanne, Switzerland, 105 pp.; 2007.

[46] Termkhajornkit P, Nawa T, Kurumisawa K. Effect of water curing conditions on the hydration degree and compressive strengths of fly ash-cement paste. Cement and Concrete Composites. 2006;28(9):781-9.

[47] Duran Atiş C. Strength properties of high-volume fly ash roller compacted and workable concrete, and influence of curing condition. Cement and Concrete Research. 2005;35(6):1112-21.

[48] FIB. The fib Model Code for Concrete Structures, Model Code 2010. Internation Federation for Structural Concrete (FIB), prepared by fib Special Activity Group 5, based on the draft published as FIB Bulletins 55 and 56, Lausanne, Switzerland; 2010.

[49] Mahadevan S, Haldar A. Probability, Reliability and Statistical Method in Engineering Design. John Wiley \& Sons; 2000.

[50] Cabral-Fonseca S, Nunes João P, Rodrigues Maria P, Eusébio Maria I. Durability of carbon fibre reinforced polymer laminates used to reinforced concrete structures. Science and Engineering of Composite Materials. 2011;18(4):201-7.

[51] Di Ludovico M, Piscitelli F, Prota A, Lavorgna M, Mensitieri G, Manfredi G. Improved mechanical properties of CFRP laminates at elevated temperatures and freeze-thaw cycling. Construction and Building Materials. 2012;31:273-83.

[52] Sciolti MS, Frigione M, Aiello MA. Wet Lay-Up Manufactured FRPs for Concrete and Masonry Repair: Influence of Water on the Properties of Composites and on Their Epoxy Components. Journal of Composites for Construction. 2010;14(6):823-33.

[53] Tuakta C, Büyüköztürk O. Deterioration of FRP/concrete bond system under variable moisture conditions quantified by fracture mechanics. Composites Part B: Engineering. 2011;42(2):145-54.

[54] Ghiassi B, Marcari G, Oliveira DV, Lourenço PB. Water degrading effects on the bond behavior in FRP-strengthened masonry. Composites Part B: Engineering. 2013;54:11-9.

[55] Savvilotidou M, Vassilopoulos AP, Frigione M, Keller T. Development of physical and mechanical properties of a cold-curing structural adhesive in a wet bridge environment. Construction and Building Materials. 2017;144:115-24.

[56] Savvilotidou M, Vassilopoulos AP, Frigione M, Keller T. Effects of aging in dry environment on physical and mechanical properties of a cold-curing structural epoxy adhesive for bridge construction. Construction and Building Materials. 2017;140:552-61.

[57] Fernandes P, Granja JL, Benedetti A, Sena-Cruz J, Azenha M. Quality control and monitoring of NSM CFRP systems: E-modulus evolution of epoxy adhesive and its relation to the pull-out force. Composites Part B: Engineering. 2015;75:95-103.

[58] Granja JL, Fernandes P, Benedetti A, Azenha M, Sena-Cruz J. Monitoring the early stiffness development in epoxy adhesives for structural strengthening. International Journal of Adhesion and Adhesives. 2015;59:77-85.

[59] El Yagoubi J, Lubineau G, Saghir S, Verdu J, Askari A. Thermomechanical and hygroelastic properties of an epoxy system under humid and cold-warm cycling conditions. Polymer Degradation and Stability. 2014;99:146-55.

[60] Frigione M, Naddeo C, Acierno D. Cold-curing epoxy resins: Aging and environmental effects. IThermal properties. Journal of polymer engineering. 2001;21(1):23-52.

[61] Moussa O, Vassilopoulos AP, de Castro J, Keller T. Time-temperature dependence of thermomechanical recovery of cold-curing structural adhesives. International Journal of Adhesion and Adhesives. 2012;35:94-101. 
Fernandes, P.; Sena-Cruz, J.; Xavier, J.; Silva, P.; Pereira, E.; Cruz, J.R. (2018) "Durability of bond in NSM CFRP-concrete systems under different environmental conditions." Composites Part B, 138: 19-34.

[62] Pritchard G. Reinforced plastics durability: CRC Press; 1999.

[63] Silva P, Fernandes P, Sena-Cruz J, Xavier J, Castro F, Soares D, et al. Effects of different environmental conditions on the mechanical characteristics of a structural epoxy. Composites Part B: Engineering. 2016;88:55-63.

[64] Sena-Cruz JM, Barros JAO. Bond Between Near-Surface Mounted Carbon-Fiber-Reinforced Polymer Laminate Strips and Concrete. Journal of Composites for Construction. 2004;8(6):519-27.

[65] Awaja F, Gilbert M, Kelly G, Fox B, Pigram PJ. Adhesion of polymers. Progress in Polymer Science. 2009;34(9):948-68.

[66] Baldan A. Adhesion phenomena in bonded joints. International Journal of Adhesion and Adhesives. 2012;38:95-116.

[67] Coelho MRF, Sena-Cruz JM, Neves LAC. A review on the bond behavior of FRP NSM systems in concrete. Construction and Building Materials. 2015;93:1157-69.

[68] FIB. Bond of reinforcement in concrete. Bulletin No. 10, The International Federation for Structural Concrete (FIB), State-of-the-art report prepared by Task Group Bond Models (former CEB Task Group 2.5), Lausanne, Switzerland, 427 pp.; 2000.

[69] Sena-Cruz JM, Barros JAO, Gettu R, Azevedo FM. Bond behavior of near surface mounted CFRP laminate strips under monotonic and cyclic loading. Journal of Composites for Construction. 2006;10(4):295-303.

[70] Ghiassi B, Xavier J, Oliveira DV, Lourenço PB. Application of digital image correlation in investigating the bond between FRP and masonry. Composite Structures. 2013;106:340-9.

[71] Rasband WS. ImageJ 1.49v, U. S. National Institutes of Health, Bethesda, Maryland, USA, http://imagej.nih.gov/ij/. 2015.

[72] Fernandes PMG, Silva PM, Sena-Cruz J. Bond and flexural behavior of concrete elements strengthened with NSM CFRP laminate strips under fatigue loading. Engineering Structures. 2015;84:350-61.

[73] Bilotta A, Ceroni F, Di Ludovico M, Nigro E, Pecce M, Manfredi G. Bond Efficiency of EBR and NSM FRP Systems for Strengthening Concrete Members. Journal of Composites for Construction. 2011;15(5):757-72.

[74] Khshain NT, Al-Mahaidi R, Abdouka K. Bond behaviour between NSM CFRP strips and concrete substrate using single-lap shear testing with epoxy adhesive. Composite Structures. 2015;132:205-14.

[75] Signor AW, VanLandingham MR, Chin JW. Effects of ultraviolet radiation exposure on vinyl ester resins: characterization of chemical, physical and mechanical damage. Polymer Degradation and Stability. 2003;79(2):359-68.

[76] Ferdous W, Manalo A, Aravinthan T, Van Erp G. Effect of ultraviolet radiation on the physical and mechanical properties of polymer matrix. 27th Biennial National Conference of the Concrete Institute of Australia (Concrete2015) in conjunction with the 69th RILEM Week; 2015. p. 630-6.

[77] Au C, Büyüköztürk O. Peel and Shear Fracture Characterization of Debonding in FRP Plated Concrete Affected by Moisture. Journal of Composites for Construction. 2006;10(1):35-47.

[78] Silva MAG, Biscaia H. Degradation of bond between FRP and RC beams. Composite Structures. 2008;85(2):164-74.

[79] Dai J-G, Yokota H, Iwanami M, Kato E. Experimental Investigation of the Influence of Moisture on the Bond Behavior of FRP to Concrete Interfaces. Journal of Composites for Construction. 2010;14(6):834-44.

[80] Benzarti K, Chataigner S, Quiertant M, Marty C, Aubagnac C. Accelerated ageing behaviour of the adhesive bond between concrete specimens and CFRP overlays. Construction and Building Materials. 2011;25(2):523-38.

[81] Choi S, Gartner AL, Etten NV, Hamilton HR, Douglas EP. Durability of Concrete Beams Externally Reinforced with CFRP Composites Exposed to Various Environments. Journal of Composites for Construction. 2012;16(1):10-20.

[82] Kabir MI, Shrestha R, Samali B. Effects of applied environmental conditions on the pull-out strengths of CFRP-concrete bond. Construction and Building Materials. 2016;114:817-30.

[83] Shrestha J, Ueda T, Zhang D. Durability of FRP Concrete Bonds and Its Constituent Properties under the Influence of Moisture Conditions. Journal of Materials in Civil Engineering. 2015;27(2):A4014009. 
[84] Colombi P, Fava G, Poggi C. Bond strength of CFRP-concrete elements under freeze-thaw cycles. Composite Structures. 2010;92(4):973-83.

[85] Leone M, Matthys S, Aiello MA. Effect of elevated service temperature on bond between FRP EBR systems and concrete. Composites Part B: Engineering. 2009;40(1):85-93.

[86] Firmo JP, Correia JR, Pitta D, Tiago C, Arruda MRT. Experimental characterization of the bond between externally bonded reinforcement (EBR) CFRP strips and concrete at elevated temperatures. Cement and Concrete Composites. 2015;60:44-54. 
Fernandes, P.; Sena-Cruz, J.; Xavier, J.; Silva, P.; Pereira, E.; Cruz, J.R. (2018) "Durability of bond in NSM CFRP-concrete systems under different environmental conditions." Composites Part B, 138: 19-34.

\section{LIST OF TABLES}

Table 1: Summary of existing studies on bond durability of EBR CFRP-concrete systems.

Table 2: Experimental program conditions for environmental tests.

Table 3: Main results obtained in the environmental tests (average values obtained from four specimens per series). 
Fernandes, P.; Sena-Cruz, J.; Xavier, J.; Silva, P.; Pereira, E.; Cruz, J.R. (2018) "Durability of bond in NSM CFRP-concrete systems under different environmental conditions." Composites Part B, 138: 19-34.

\section{LIST OF FIGURES}

Figure 1: Temperatures and RH registered over the time of exposure under real environments: (a) "Port of Leixões" (RA); (b) University of Minho - Guimarães (RB).

Figure 2: Direct pullout test (DPT): (a) specimen's geometry and test configuration [units: mm]; (b) photo.

Figure 3: Timetable of developed experimental programme.

Figure 4: Development bond length: maximum pullout force versus bond length.

Figure 5: (a) Evolution of concrete compressive strength along the time; (b) Compressive strength variation of concrete.

Figure 6: Tensile properties of the CFRP laminate: (a) tensile strength; (b) elastic modulus.

Figure 7: Tensile properties of the epoxy adhesive: (a) tensile strength; (b) elastic modulus.

Figure 8: Region of interest (ROI) of DPT tests coupled with DIC technique.

Figure 9: Pullout force-loaded end slip behaviour and strain fields in the ROI of NSM CFRP-concrete specimen (LE480_3).

Figure 10: Longitudinal strains $\left(\varepsilon_{x}\right)$ in specimen LE480_3 for different load levels (A-F in Figure 9): (a) longitudinal profile P1; (b) transverse profile P2.

Figure 11: Crack pattern at different load levels up to the peak pullout force for the specimen RA720R_3.

Figure 12: Typical average pullout force versus loaded end slip responses of specimens subjected to: (a) tap water; (b) real environment $\mathrm{A}$.

Figure 13: Evolution of the maximum pullout force for reference series throughout the exposure time.

Figure 14: Maximum pullout force variation due to the effect of different environmental conditions.

Figure 15: Comparison between the variations of the $f_{a u}$ of the epoxy and $F_{\text {lmax }}$ of the NSM CFRP-concrete system for distinct environmental conditions.

Figure 16: Observed failure modes: (a) and (b) I-FA: debonding at the interface CFRP/adhesive; (c) I-FA+CC: debonding at the interface CFRP/adhesive with concrete cracking; (d) I-FA+CS: debonding at the interface CFRP/adhesive with concrete splitting; (e) C-C: cohesive failure in concrete; (f) I-AC+CS: debonding at the interface adhesive/concrete with concrete splitting. 
Table 1: Summary of existing studies on bond durability of EBR CFRP-concrete systems.

\begin{tabular}{|c|c|c|c|c|c|}
\hline \multirow[b]{2}{*}{ Reference } & \multirow[b]{2}{*}{ FRP system } & \multirow[b]{2}{*}{ Environmental conditions } & \multirow[b]{2}{*}{ Test method } & \multicolumn{2}{|c|}{ Results } \\
\hline & & & & $\begin{array}{l}\text { Bond strength variation in } \\
\text { comparison with control specimens }\end{array}$ & Failure mode (FM) \\
\hline \multirow[b]{2}{*}{ [77] } & \multirow{2}{*}{$\begin{array}{l}\text { CFRP strip } \\
\text { and epoxy } \\
\text { adhesive }\end{array}$} & \multirow{2}{*}{$\begin{array}{l}\text { Water immersion up to } 8 \text { weeks at } \\
23{ }^{\circ} \mathrm{C} \text { and } 50{ }^{\circ} \mathrm{C}\end{array}$} & Peel test & $\begin{array}{l}\text { Bond strength decreases up to } 60 \% \\
\text { in peel fracture toughness }\end{array}$ & \multirow{2}{*}{$\begin{array}{l}\text { Debonding mode by concrete } \\
\text { delamination for the dry } \\
\text { specimens changes to debonding } \\
\text { at the interface epoxy/concrete for } \\
\text { the wet specimens }\end{array}$} \\
\hline & & & Shear test & $\begin{array}{l}\text { Bond strength decreases } 10 \% \text { and } \\
50 \% \text { in shear fracture toughness for } \\
23{ }^{\circ} \mathrm{C} \text { and } 50{ }^{\circ} \mathrm{C} \text {, respectively }\end{array}$ & \\
\hline [78] & $\begin{array}{l}\text { CFRP strip } \\
\text { and epoxy } \\
\text { adhesive }\end{array}$ & $\begin{array}{l}\text { Moisture cycles (each cycle: } 24 \mathrm{~h} \\
\text { with RH ranging between } 20 \% \text { and } \\
90 \% \text { ) and salt fog cycles (each cycle: } \\
16 \mathrm{~h} \text { of drying, followed by } 8 \mathrm{~h} \text { of fog } \\
\text { at } 35^{\circ} \mathrm{C} \text { ) up to } 10,000 \mathrm{~h} \text { and } 6000 \mathrm{~h} \\
\text { of ageing, respectively }\end{array}$ & Four-point bending test & $\begin{array}{l}\text { Bond strength decreases up to } \\
\text { around } 19 \% \text { for both exposure } \\
\text { conditions }\end{array}$ & $\begin{array}{l}\text { Moisture cycles no change the } \\
\text { FM (failure in the concrete } \\
\text { substrate), while for salt fog } \\
\text { cycles the FM changed from the } \\
\text { concrete to the debonding at the } \\
\text { interface concrete/adhesive }\end{array}$ \\
\hline [79] & $\begin{array}{l}\text { CFRP sheet } \\
\text { with two } \\
\text { types of } \\
\text { adhesives } \\
\end{array}$ & $\begin{array}{l}\text { Wet-dry cycles in sea water at } 60{ }^{\circ} \mathrm{C} \\
\text { during } 8,14 \text { and } 24 \text { months }(\text { each } \\
\text { cycle: } 4 \text { days of wetting and } 3 \text { days of } \\
\text { drying) }\end{array}$ & Four-point bending test & $\begin{array}{l}\text { Flexural strength decreases up to } \\
20 \% \text { and increases up to } 35 \% \text { for } \\
\text { normal and flexible adhesives, } \\
\text { respectively }\end{array}$ & $\begin{array}{l}\text { Debonding at the interface } \\
\text { primer/concrete (almost no } \\
\text { concrete was attached to the } \\
\text { peeled off FRP) }\end{array}$ \\
\hline$[80]$ & $\begin{array}{l}\text { CFRP sheet } \\
\text { and strip with } \\
\text { epoxy } \\
\text { adhesive }\end{array}$ & $\begin{array}{l}\text { Constant hydrothermal conditions at } \\
\text { a temperature of } 40^{\circ} \mathrm{C} \text { and } \mathrm{RH} \text { of } \\
95 \% \text { over a period of } 13 \text { months }\end{array}$ & Shear test & $\begin{array}{l}\text { No significant evolution on the } \\
\text { maximum shear load was observed } \\
\text { (10-15\% increase in shear strength) }\end{array}$ & $\begin{array}{l}\text { Changes from a cohesive FM in } \\
\text { concrete to a cohesive failure } \\
\text { within the epoxy joint for CFRP } \\
\text { strips and to interfacial } \\
\text { concrete/adhesive failure for } \\
\text { CFRP sheets }\end{array}$ \\
\hline [81] & $\begin{array}{l}\text { CFRP sheet } \\
\text { and strip with } \\
\text { different } \\
\text { adhesives }\end{array}$ & $\begin{array}{l}\text { Immersion in: tap water at } 30,40,50 \\
\text { and } 60{ }^{\circ} \mathrm{C} \text {; chloride and alkali } \\
\text { solution at } 50{ }^{\circ} \mathrm{C} \text {; UV/water at } 50{ }^{\circ} \mathrm{C} \text {; } \\
\text { salty water in outdoor exposure, } \\
\text { during } 6,12 \text {, and } 18 \text { months }\end{array}$ & Three-point bending test & $\begin{array}{l}\text { Flexural strength decreases up to } \\
68 \%\end{array}$ & $\begin{array}{l}\text { The FM changed from adhesive } \\
\text { in the control specimens to } \\
\text { interlaminar composite failure in } \\
\text { the exposed specimens }\end{array}$ \\
\hline [82] & $\begin{array}{l}\text { CFRP strip } \\
\text { and epoxy } \\
\text { adhesive }\end{array}$ & $\begin{array}{l}\text { Wet/dry cycles ( } 1 \text { week wetting and } 1 \\
\text { week drying), temperature cycles }\end{array}$ & Shear test & $\begin{array}{l}\text { Bond strength increases } 12 \% \text { and } \\
10 \% \text { for WD and TC cycles, } \\
\text { respectively; bond strength }\end{array}$ & $\begin{array}{l}\text { No significant changes on the FM } \\
\text { for TC cycles; the failure mode } \\
\text { changed from cohesive in }\end{array}$ \\
\hline
\end{tabular}




\begin{tabular}{|c|c|c|c|c|c|}
\hline & & $\begin{array}{l}\left(30{ }^{\circ} \mathrm{C} \text { to } 40{ }^{\circ} \mathrm{C}\right) \text { and outdoor } \\
\text { environment for up } 18 \text { months }\end{array}$ & & $\begin{array}{l}\text { decreases } 15 \% \text { for outdoor } \\
\text { environment }\end{array}$ & $\begin{array}{l}\text { concrete to cohesive in adhesive } \\
\text { with thinner layer of concrete or } \\
\text { no concrete attached to debonded } \\
\text { CFRP for WD cycles and outdoor } \\
\text { environment }\end{array}$ \\
\hline$[83]$ & $\begin{array}{l}\text { CFRP sheet } \\
\text { and epoxy } \\
\text { adhesive }\end{array}$ & $\begin{array}{l}\text { Water immersion and wet-dry cycles } \\
\text { for a maximum period of up to } 24 \\
\text { and } 18 \text { months, respectively }\end{array}$ & Shear test & $\begin{array}{l}\text { Bond strength decreases up to } 32 \\
\text { and } 12 \% \text { for high-strength and } \\
\text { normal-strength concrete } \\
\text { substrates, respectively, after } \\
\text { continuous immersion }\end{array}$ & $\begin{array}{l}\text { The FM changed from cohesive } \\
\text { in concrete to primer-concrete } \\
\text { mixed failure for normal-strength } \\
\text { concrete, whereas in case of high- } \\
\text { strength concrete the failure } \\
\text { shifted from primer-concrete } \\
\text { mixed failure to complete } \\
\text { adhesion failure }\end{array}$ \\
\hline [7] & $\begin{array}{l}\text { CFRP sheet } \\
\text { and strip with } \\
\text { epoxy } \\
\text { adhesive }\end{array}$ & $\begin{array}{l}\text { Salted water immersion and freeze- } \\
\text { thaw cycles }(16 \mathrm{~h} \text { of freezing at }-18 \\
\left.{ }^{\circ} \mathrm{C} \text { and } 8 \mathrm{~h} \text { of thawing at }+15^{\circ} \mathrm{C}\right) \\
\text { during } 120 \text { and } 300 \text { days, } \\
\text { respectively }\end{array}$ & Four-point bending test & $\begin{array}{l}\text { Bond strength had a significant } \\
\text { reduction of } \approx 25 \% \text { after } 300 \text { freeze- } \\
\text { thaw cycles for both CFRP sheet } \\
\text { and strip; specimens strengthened } \\
\text { with CFRP sheet immersed in salt } \\
\text { water had a significant decrease of } \\
48 \% \text {, while for CFRP strip a slight } \\
\text { increase of } 4.6 \% \text { was observed }\end{array}$ & $\begin{array}{l}\text { No changes on the FM for freeze- } \\
\text { thaw cycles, while for both CFRP } \\
\text { sheet and strip specimens the FM } \\
\text { changed from cohesive in } \\
\text { concrete to debonding at the } \\
\text { interface concrete/adhesive }\end{array}$ \\
\hline [84] & $\begin{array}{l}\text { CFRP sheet } \\
\text { and strip with } \\
\text { epoxy } \\
\text { adhesive }\end{array}$ & $\begin{array}{l}100 \text { and } 200 \text { freeze-thaw cycles from } \\
-18 \text { to }+4{ }^{\circ} \mathrm{C} \text { with a duration of about } \\
5 \text { h each }\end{array}$ & Shear test & $\begin{array}{l}\text { Freeze-thaw cycles did not yield to } \\
\text { noticeably degradation on the bond } \\
\text { strength }\end{array}$ & $\begin{array}{l}\text { No changes on the FM was } \\
\text { observed. The failure was } \\
\text { cohesive in concrete with a } \\
\text { uniform concrete layer attached to } \\
\text { the CFRP reinforcement }\end{array}$ \\
\hline [85] & $\begin{array}{l}\text { CFRP strip or } \\
\text { sheet and } \\
\text { epoxy } \\
\text { adhesive }\end{array}$ & $\begin{array}{l}\text { Steady-state conditions at different } \\
\text { testing temperatures: } 20,50,65 \text { and } \\
80{ }^{\circ} \mathrm{C}\end{array}$ & Shear test & $\begin{array}{l}\text { For CFRP sheets the bond strength } \\
\text { increase up to } 65^{\circ} \mathrm{C}(24 \% \text { increase } \\
\left.\text { at } 50{ }^{\circ} \mathrm{C} \text { and } 7 \% \text { at } 65^{\circ} \mathrm{C}\right) \text {, whereas } \\
\text { at } 80^{\circ} \mathrm{C} \text { a } 11 \% \text { reduction was } \\
\text { observed; for CFRP strips the bond } \\
\text { strength decrease } 42 \% \text { at } 50{ }^{\circ} \mathrm{C} \text { and } \\
25 \% \text { at } 80^{\circ} \mathrm{C}\end{array}$ & $\begin{array}{l}\text { In the case of the CFRP laminates } \\
\text { no changes on the FM were } \\
\text { observed. In the case of the CFRP } \\
\text { sheets the type of failure changed } \\
\text { with increasing test temperature: } \\
\text { cohesion failure within the } \\
\text { concrete at } 50{ }^{\circ} \mathrm{C} \text { and adhesion } \\
\text { failure at the interface between } \\
\text { adhesive and FRP at } 80^{\circ} \mathrm{C}\end{array}$ \\
\hline
\end{tabular}




\begin{tabular}{l|l|l|l|l}
\hline & & $\begin{array}{l}\text { Steady-state conditions at different } \\
\text { testing temperatures: } 20,55,90 \text { and } \\
120^{\circ} \mathrm{C} \text {; transient conditions up to } \\
25 \%, 50 \% \text { or } 75 \% \text { of their ambient } \\
\text { temperature strength }\end{array}$ & $\begin{array}{l}\text { CFRP strip } \\
\text { and epoxy } \\
\text { adhesive }\end{array}$ & $\begin{array}{l}\text { Shear test } \\
\text { [86] }\end{array}$
\end{tabular}


Table 2: Experimental program conditions for environmental tests.

\begin{tabular}{|c|c|c|}
\hline Series & Environmental conditions & Subseries denomination \\
\hline $\mathrm{LE}$ & $\begin{array}{l}\text { Laboratory environment (Reference) (average temperature of } \\
20{ }^{\circ} \mathrm{C} \text { and relative humidity of } 56 \pm 10 \% \text { ) }\end{array}$ & $\begin{array}{l}\text { LE0 } \\
\text { LE240 } \\
\text { LE480 }\end{array}$ \\
\hline TW & Tap water immersion $\left(22 \pm 2^{\mathrm{a}}{ }^{\circ} \mathrm{C}\right)$ & $\begin{array}{l}\text { TW240 } \\
\text { TW480 }\end{array}$ \\
\hline $\mathrm{CW}$ & Tap water immersion $\left(22 \pm 2^{\mathrm{a}}{ }^{\circ} \mathrm{C}\right)$ with $3.5 \%$ of $\mathrm{NaCl}$ & $\begin{array}{l}\text { CW240 } \\
\text { CW480 }\end{array}$ \\
\hline WD & Wet/dry cycles in tap water $\left(22 \pm 2^{\mathrm{a}}{ }^{\circ} \mathrm{C}\right)$ with $3.5 \%$ of $\mathrm{NaCl}$ & $\begin{array}{l}\text { WD240 } \\
\text { WD480 }\end{array}$ \\
\hline TCA & $\begin{array}{l}\text { Temperature cycles A: temperatures ranged between }-15^{\circ} \mathrm{C} \text { and } \\
+60^{\circ} \mathrm{C}\end{array}$ & $\begin{array}{l}\text { TCA120 } \\
\text { TCA120R } \\
\text { TCA240 } \\
\text { TCA240R } \\
\end{array}$ \\
\hline TCB & $\begin{array}{l}\text { Temperature cycles } \mathrm{B} \text { : temperatures ranged between }+20^{\circ} \mathrm{C} \text { and } \\
+80^{\circ} \mathrm{C}\end{array}$ & $\begin{array}{l}\text { TCB } 180 \\
{\text { TCB } 180 R^{b}}^{b}\end{array}$ \\
\hline FT & $\begin{array}{l}\text { Freeze-thaw cycles: temperature ranged between }-18^{\circ} \mathrm{C} \text { and } \\
+20^{\circ} \mathrm{C}\end{array}$ & $\begin{array}{l}\text { FT120 } \\
\text { FT120R } \\
\text { FT240 } \\
\text { FT240R }\end{array}$ \\
\hline RA & $\begin{array}{l}\text { Real environment A: exposed to airborne salt (tidal and spray } \\
\text { zones) - warm mediterranean/dry-summer subtropical } \\
\text { environment (Port of Leixões) }\end{array}$ & $\begin{array}{l}\text { RA720 } \\
\text { RA720R }\end{array}$ \\
\hline $\mathrm{RB}$ & $\begin{array}{l}\text { Real environment B: exposed to warm and temperate } \\
\text { environment (Guimarães city) }\end{array}$ & $\begin{array}{l}\text { RB720 } \\
\text { RB720R }^{b}\end{array}$ \\
\hline
\end{tabular}

a These values are the standard deviation of the corresponding temperature.

${ }^{\mathrm{b}}$ Reference series (kept in laboratory environment) tested at the same time of the corresponding aged series. 
Fernandes, P.; Sena-Cruz, J.; Xavier, J.; Silva, P.; Pereira, E.; Cruz, J.R. (2018) "Durability of bond in NSM CFRP-concrete systems under different environmental conditions." Composites Part B, 138: 19-34.

Table 3: Main results obtained in the environmental tests (average values obtained from four specimens per series).

\begin{tabular}{|c|c|c|c|c|}
\hline Series & $F_{\text {lmax }}[\mathrm{kN}]$ & $s_{\text {lmax }}[\mathrm{mm}]$ & $\tau_{\max }[\mathrm{MPa}]$ & Failure mode \\
\hline LE0 & $24.25(1.6 \%)$ & $0.55(11.1 \%)$ & $17.73(1.6 \%)$ & $\operatorname{I-FA}(3)^{*}$ \\
\hline TCA120R & $28.24(6.8 \%)$ & $0.69(21.4 \%)$ & $20.65(6.8 \%)$ & $\mathrm{I}-\mathrm{FA}(2)^{*} ; \mathrm{I}-\mathrm{FA}+\mathrm{CS}(1)^{*}$ \\
\hline TCA240R & $27.48(3.4 \%)$ & $0.70(2.7 \%)$ & $20.08(3.4 \%)$ & $\mathrm{I}-\mathrm{FA}(4) *$ \\
\hline $\begin{array}{l}\text { LE240 } \\
\text { FT120R }\end{array}$ & $26.71(3.2 \%)$ & $0.70(3.9 \%)$ & $19.52(3.2 \%)$ & $\mathrm{I}-\mathrm{FA}(4)^{*}$ \\
\hline FT240R & $28.77(3.3 \%)$ & $0.79(5.5 \%)$ & $21.03(3.3 \%)$ & $\mathrm{I}-\mathrm{FA}(3)^{*} ; \mathrm{I}-\mathrm{FA}+\mathrm{CC}(1)^{*}$ \\
\hline LE480 & $26.72(4.5 \%)$ & $0.58(12.0 \%)$ & $19.53(4.5 \%)$ & $\mathrm{I}-\mathrm{FA}(2)^{*} ; \mathrm{I}-\mathrm{FA}+\mathrm{CC}(1)^{*}$ \\
\hline TCB180R & $28.59(3.3 \%)$ & $0.69(6.2 \%)$ & $20.90(3.3 \%)$ & $\mathrm{I}-\mathrm{FA}(3)^{*} ; \mathrm{C}-\mathrm{C}(1)^{*}$ \\
\hline $\begin{array}{l}\text { RA720R } \\
\text { RB720R }\end{array}$ & $28.63(1.9 \%)$ & $0.59(9.4 \%)$ & $20.93(1.9 \%)$ & $\mathrm{I}-\mathrm{FA}(4) *$ \\
\hline TW240 & $26.93(0.5 \%)$ & $0.69(9.2 \%)$ & $19.68(0.5 \%)$ & $\begin{array}{l}\mathrm{I}-\mathrm{FA}+\mathrm{CS}(1)^{*} ; \mathrm{C}-\mathrm{C}(1)^{*} ; \\
\mathrm{I}-\mathrm{FA}+\mathrm{CC}(1)^{*} ; \mathrm{I}-\mathrm{FA}(1)^{*}\end{array}$ \\
\hline TW480 & $26.94(1.2 \%)$ & $0.66(10.1 \%)$ & $19.69(1.2 \%)$ & $\mathrm{I}-\mathrm{FA}(3)^{*} ; \mathrm{I}-\mathrm{FA}+\mathrm{CC}(1)^{*}$ \\
\hline CW240 & $28.01(3.9 \%)$ & $0.70(11.2 \%)$ & $20.48(3.9 \%)$ & $\mathrm{I}-\mathrm{FA}+\mathrm{CC}(3)^{*} ; \mathrm{I}-\mathrm{FA}(1)^{*}$ \\
\hline CW480 & $27.58(3.7 \%)$ & $0.73(13.5 \%)$ & $20.16(3.7 \%)$ & $\mathrm{I}-\mathrm{FA}(2)^{*} ; \mathrm{I}-\mathrm{FA}+\mathrm{CC}(2)^{*}$ \\
\hline WD240 & $27.93(3.6 \%)$ & $0.70(4.4 \%)$ & $20.41(3.6 \%)$ & $\begin{array}{l}\mathrm{I}-\mathrm{FA}+\mathrm{CS}(2)^{*} ; \mathrm{C}-\mathrm{C}(1)^{*} \\
\mathrm{I}-\mathrm{FA}+\mathrm{CC}(1)^{*}\end{array}$ \\
\hline WD480 & $26.34(3.0 \%)$ & $0.66(6.5 \%)$ & $19.25(3.0 \%)$ & $\mathrm{I}-\mathrm{FA}(3) * ; \mathrm{I}-\mathrm{FA}+\mathrm{CC}(1)^{*}$ \\
\hline TCA120 & $29.88(1.6 \%)$ & $0.75(7.6 \%)$ & $21.84(1.6 \%)$ & $\mathrm{I}-\mathrm{FA}+\mathrm{CS}(2)^{*} ; \mathrm{I}-\mathrm{FA}(2)^{*}$ \\
\hline TCA240 & $29.75(1.9 \%)$ & $0.76(7.3 \%)$ & $21.75(1.9 \%)$ & $\mathrm{I}-\mathrm{FA}+\mathrm{CC}(2)^{*} ; \mathrm{I}-\mathrm{FA}(2)^{*}$ \\
\hline TCB 180 & $28.64(4.0 \%)$ & $0.71(10.7 \%)$ & $20.94(4.0 \%)$ & $\mathrm{I}-\mathrm{FA}(4)^{*}$ \\
\hline FT120 & $28.63(1.7 \%)$ & $0.79(5.5 \%)$ & $20.92(1.7 \%)$ & $\mathrm{C}-\mathrm{C}(4)^{*}$ \\
\hline FT240 & $27.40(5.2 \%)$ & $0.72(11.5 \%)$ & $20.03(5.2 \%)$ & $\mathrm{I}-\mathrm{AC}+\mathrm{CS}(3)^{*} ; \mathrm{I}-\mathrm{FA}+\mathrm{CS}(1)^{*}$ \\
\hline RA720 & $25.34(4.6 \%)$ & $0.56(10.9 \%)$ & $18.52(4.6 \%)$ & $\mathrm{I}-\mathrm{FA}(3)^{*} ; \mathrm{I}-\mathrm{FA}+\mathrm{CC}(1)^{*}$ \\
\hline RB720 & $25.31(1.0 \%)$ & $0.56(9.2 \%)$ & $18.50(1 \%)$ & $\mathrm{I}-\mathrm{FA}(4) *$ \\
\hline
\end{tabular}

Notes: the percentages values between parentheses are the corresponding coefficients of variation; *the value between parentheses is the number of specimens with this type of failure mode. 
Fernandes, P.; Sena-Cruz, J.; Xavier, J.; Silva, P.; Pereira, E.; Cruz, J.R. (2018) "Durability of bond in NSM CFRP-concrete systems under different environmental conditions.” Composites Part B, 138: 19-34.

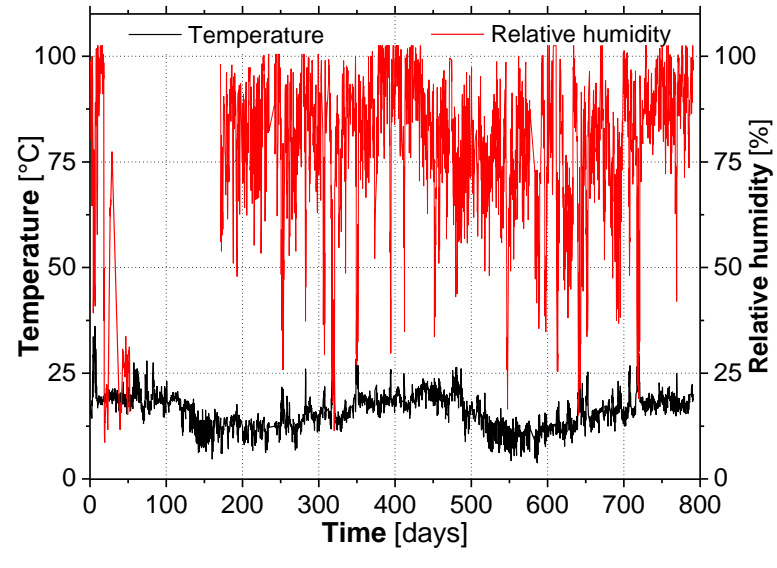

(a)

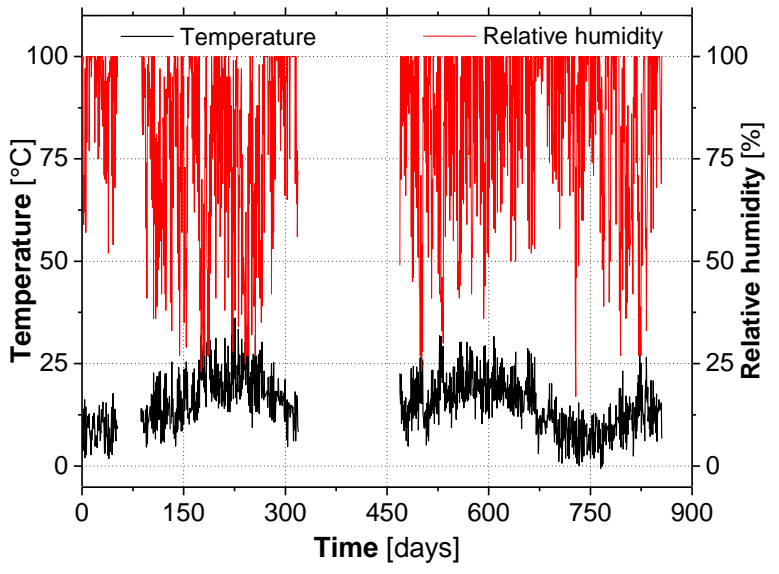

(b)

Figure 1: Temperatures and RH registered over the time of exposure under real environments: (a) "Port of Leixões" (RA); (b) University of Minho - Guimarães (RB). 


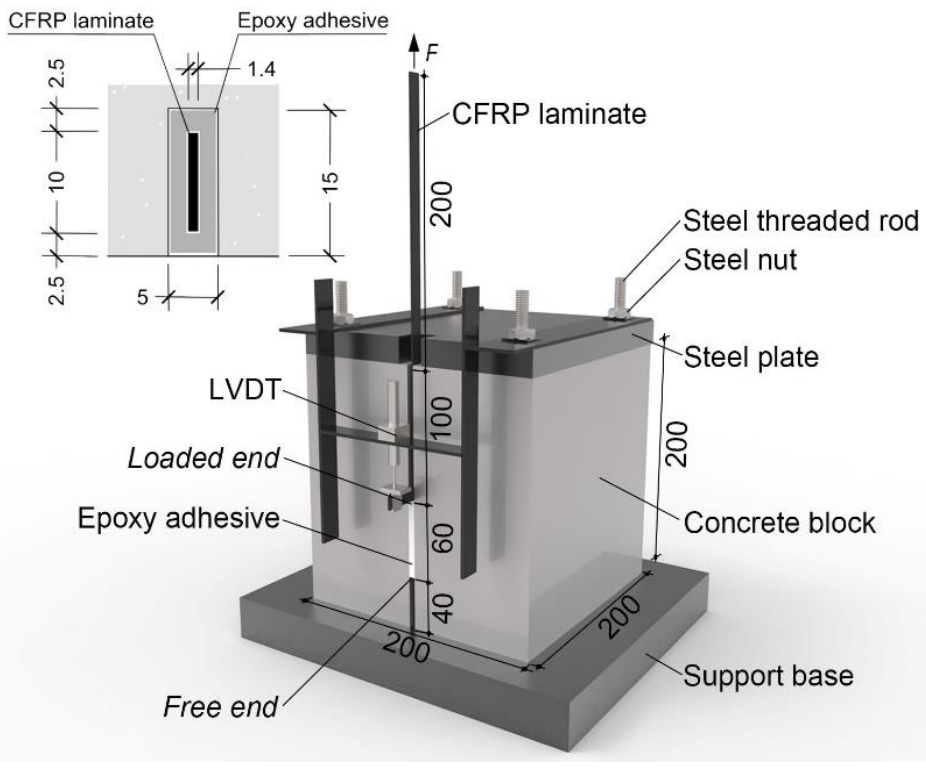

(a)

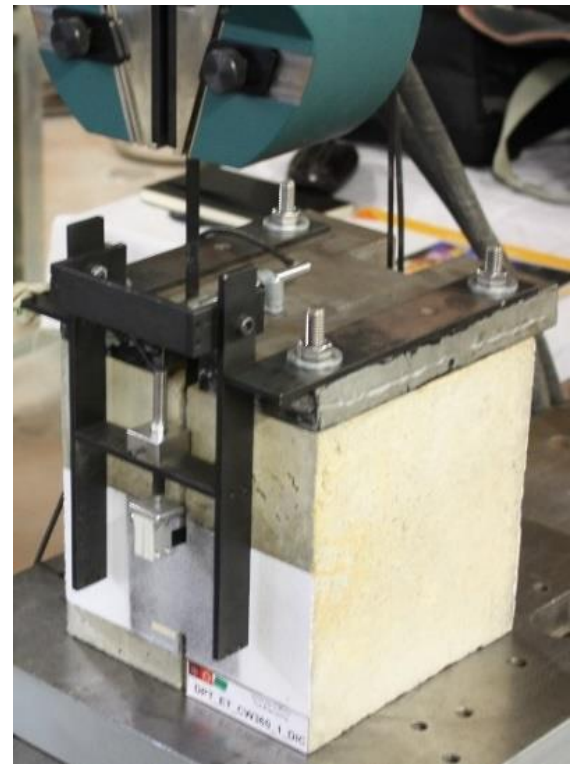

(b)

Figure 2: Direct pullout test (DPT): (a) specimen's geometry and test configuration [units: mm]; (b) photo. 
Fernandes, P.; Sena-Cruz, J.; Xavier, J.; Silva, P.; Pereira, E.; Cruz, J.R. (2018) "Durability of bond in NSM CFRP-concrete systems under different environmental conditions." Composites Part B, 138: 19-34.

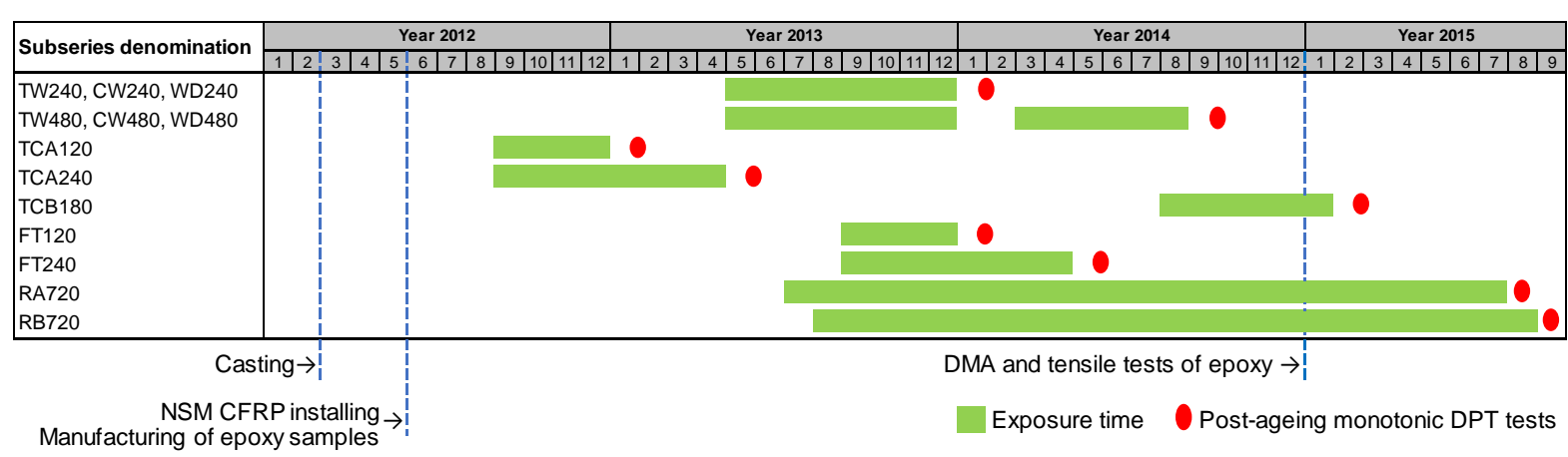

Figure 3: Timetable of developed experimental programme. 
Fernandes, P.; Sena-Cruz, J.; Xavier, J.; Silva, P.; Pereira, E.; Cruz, J.R. (2018) "Durability of bond in NSM CFRP-concrete systems under different environmental conditions." Composites Part B, 138: 19-34.

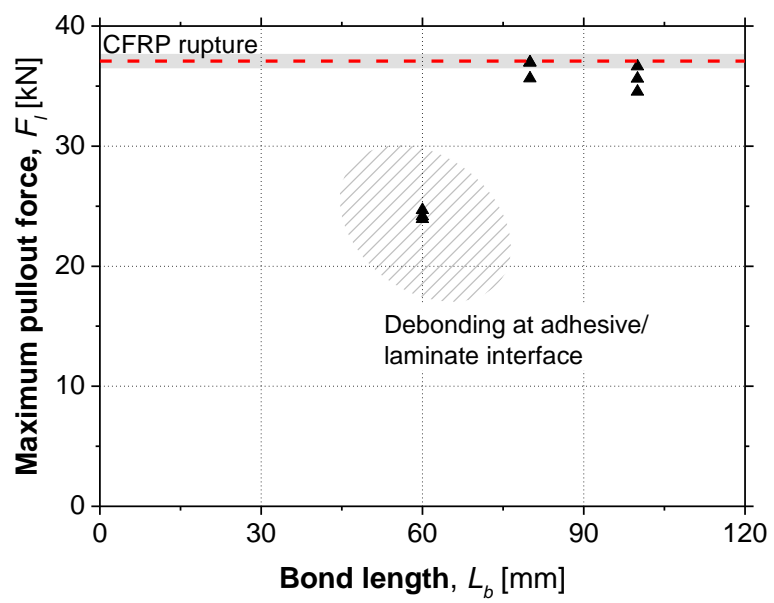

Figure 4: Development bond length: maximum pullout force versus bond length. 
Fernandes, P.; Sena-Cruz, J.; Xavier, J.; Silva, P.; Pereira, E.; Cruz, J.R. (2018) "Durability of bond in NSM CFRP-concrete systems under different environmental conditions." Composites Part B, 138: 19-34.

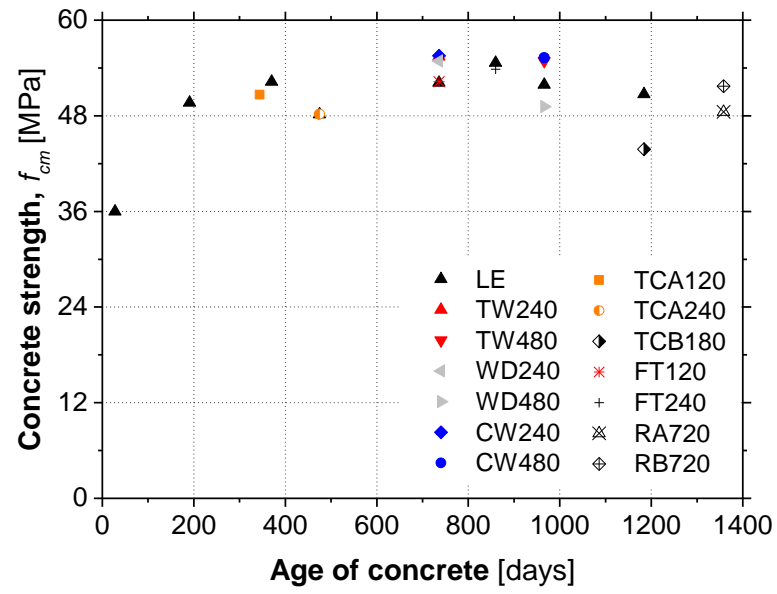

(a)

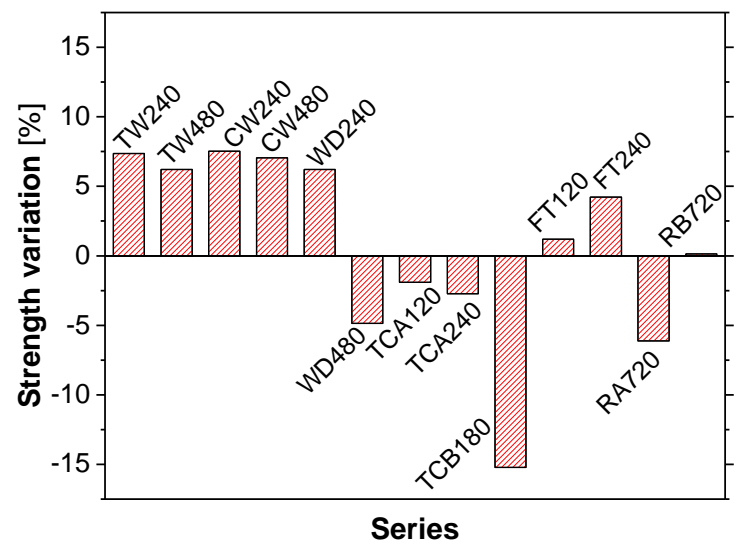

(b)

Figure 5: (a) Evolution of concrete compressive strength along the time; (b) Compressive strength variation of concrete. 
Fernandes, P.; Sena-Cruz, J.; Xavier, J.; Silva, P.; Pereira, E.; Cruz, J.R. (2018) "Durability of bond in NSM CFRP-concrete systems under different environmental conditions." Composites Part B, 138: 19-34.

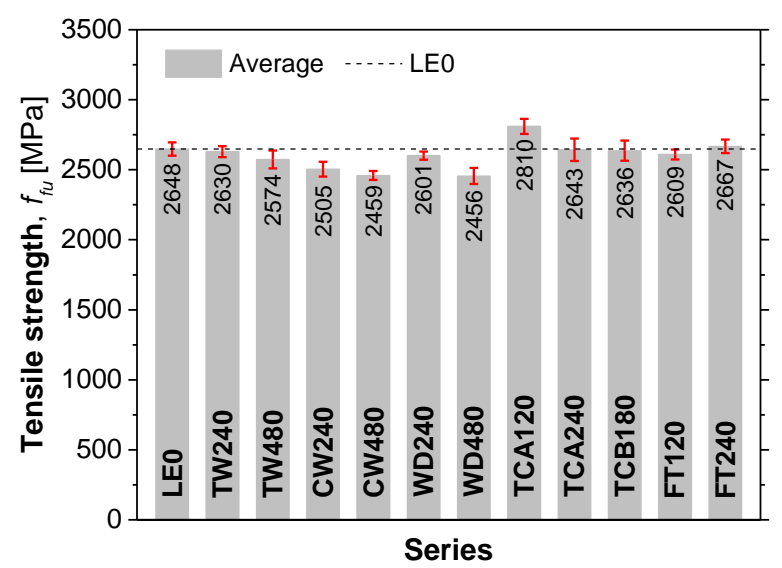

(a)

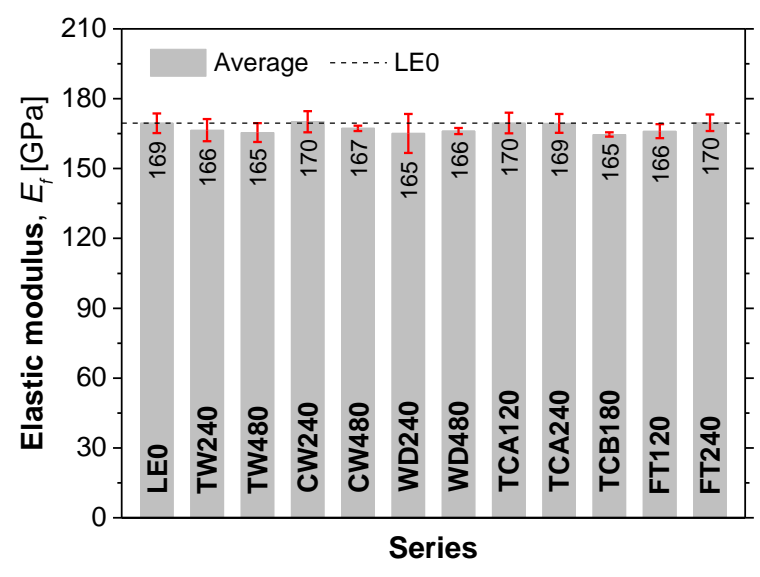

(b)

Figure 6: Tensile properties of the CFRP laminate: (a) tensile strength; (b) elastic modulus. 
Fernandes, P.; Sena-Cruz, J.; Xavier, J.; Silva, P.; Pereira, E.; Cruz, J.R. (2018) "Durability of bond in NSM CFRP-concrete systems under different environmental conditions." Composites Part B, 138: 19-34.

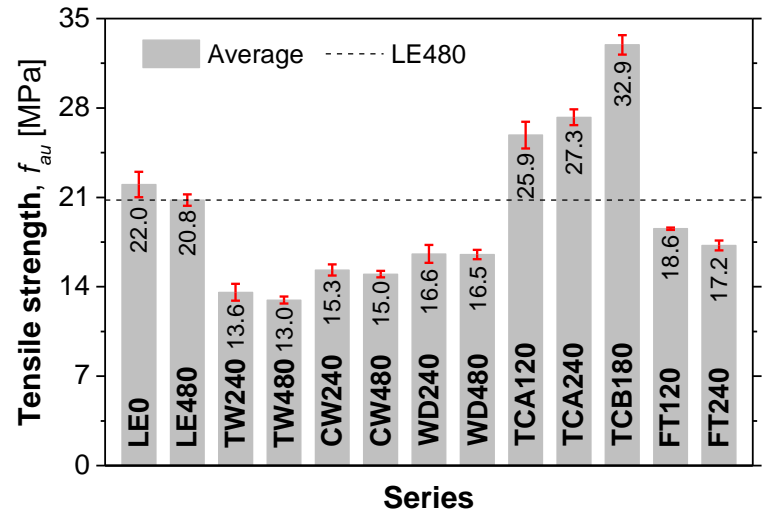

(a)

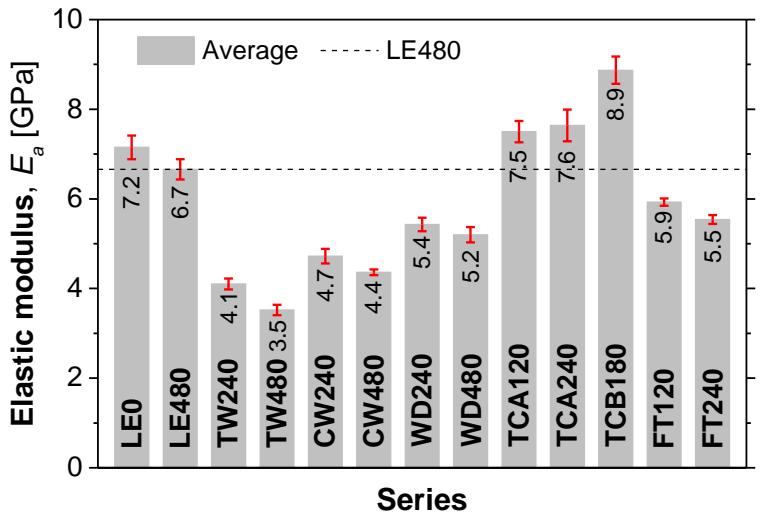

(b)

Figure 7: Tensile properties of the epoxy adhesive: (a) tensile strength; (b) elastic modulus. 
Fernandes, P.; Sena-Cruz, J.; Xavier, J.; Silva, P.; Pereira, E.; Cruz, J.R. (2018) "Durability of bond in NSM CFRP-concrete systems under different environmental conditions." Composites Part B, 138: 19-34.

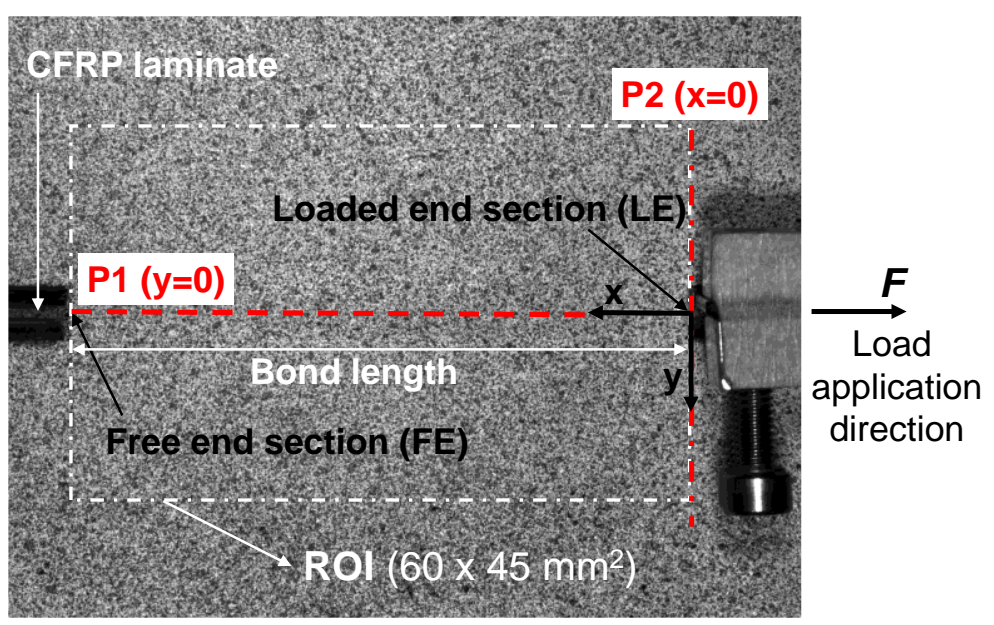

Figure 8: Region of interest (ROI) of DPT tests coupled with DIC technique. 
Fernandes, P.; Sena-Cruz, J.; Xavier, J.; Silva, P.; Pereira, E.; Cruz, J.R. (2018) "Durability of bond in NSM CFRP-concrete systems under different environmental conditions." Composites Part B, 138: 19-34.

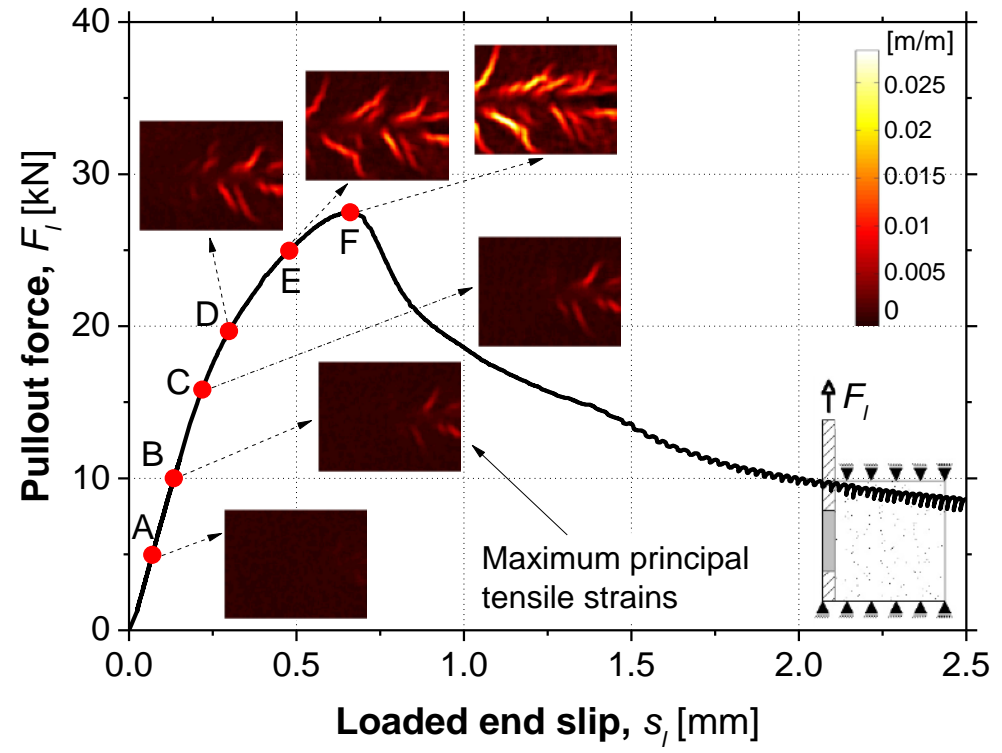

Figure 9: Pullout force-loaded end slip behaviour and strain fields in the ROI of NSM CFRP-concrete specimen (LE480_3). 


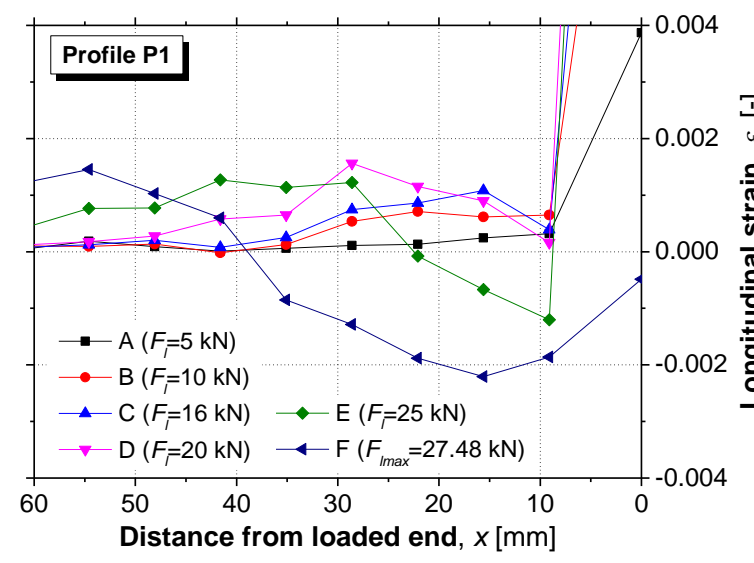

(a)

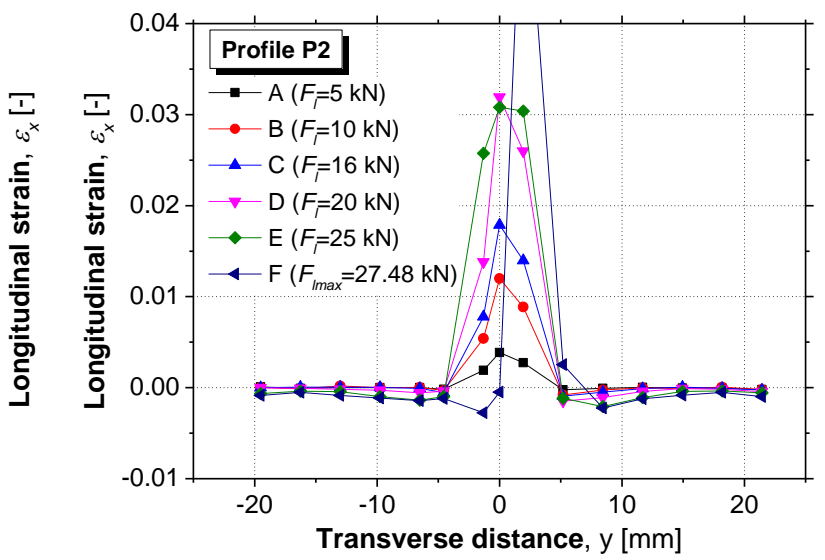

(b)

Figure 10: Longitudinal strains $\left(\varepsilon_{x}\right)$ in specimen LE480_3 for different load levels (A-F in Figure 9):

(a) longitudinal profile P1; (b) transverse profile P2. 
Fernandes, P.; Sena-Cruz, J.; Xavier, J.; Silva, P.; Pereira, E.; Cruz, J.R. (2018) "Durability of bond in NSM CFRP-concrete systems under different environmental conditions." Composites Part B, 138: 19-34.

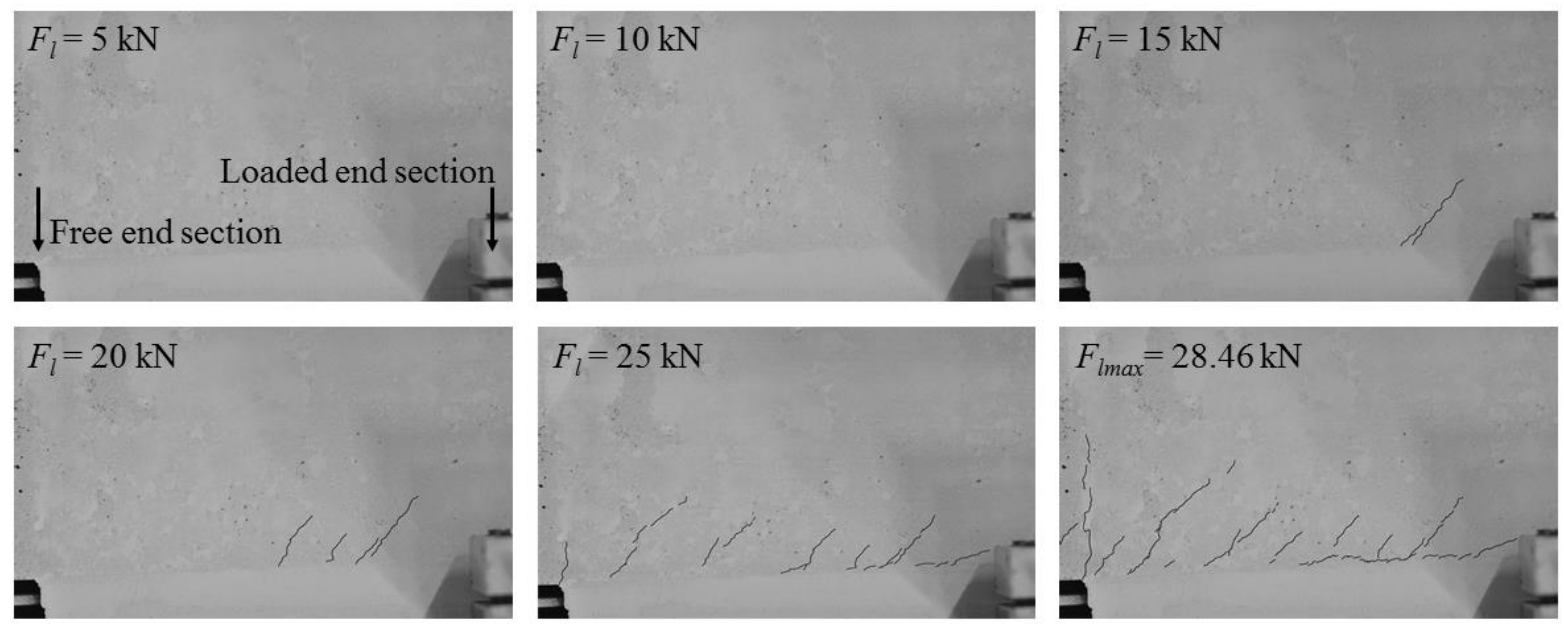

Figure 11: Crack pattern at different load levels up to the peak pullout force for the specimen RA720R_3. 
Fernandes, P.; Sena-Cruz, J.; Xavier, J.; Silva, P.; Pereira, E.; Cruz, J.R. (2018) "Durability of bond in NSM CFRP-concrete systems under different environmental conditions." Composites Part B, 138: 19-34.

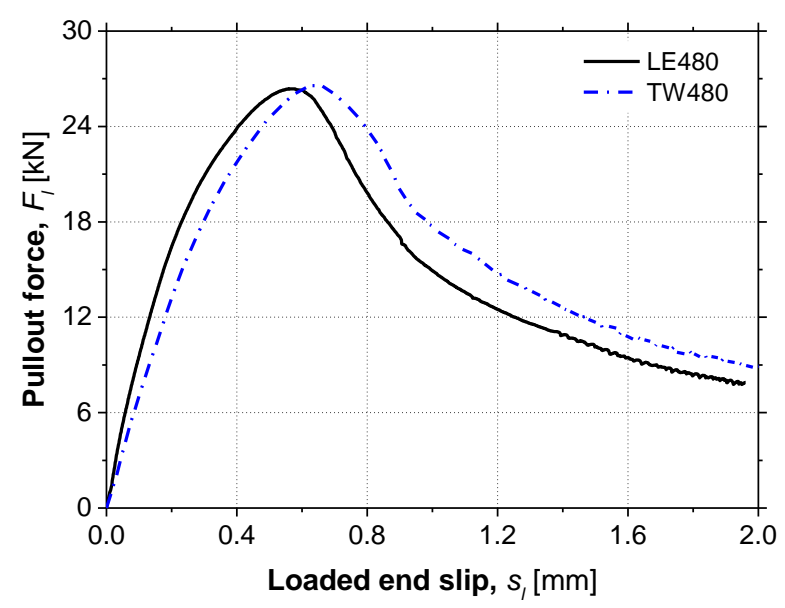

(a)

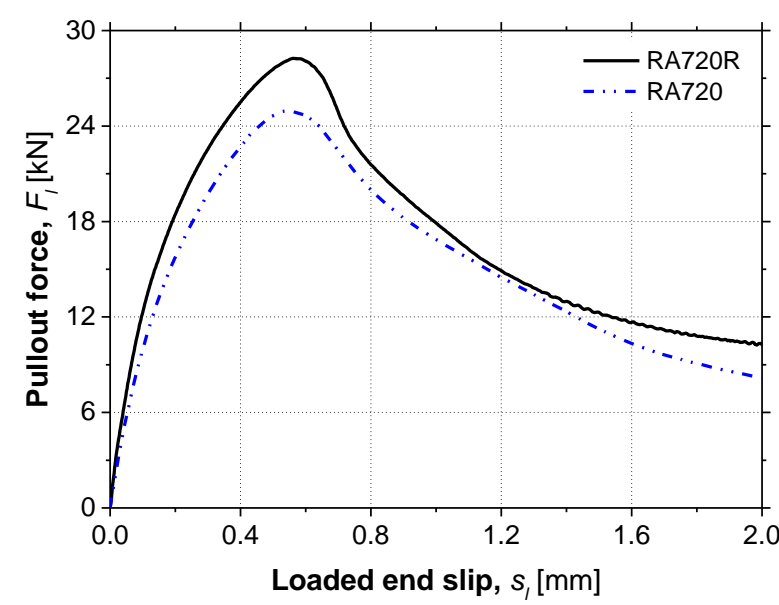

(b)

Figure 12: Typical average pullout force versus loaded end slip responses of specimens subjected to: (a) tap water; (b) real environment A. 
Fernandes, P.; Sena-Cruz, J.; Xavier, J.; Silva, P.; Pereira, E.; Cruz, J.R. (2018) "Durability of bond in NSM CFRP-concrete systems under different environmental conditions." Composites Part B, 138: 19-34.

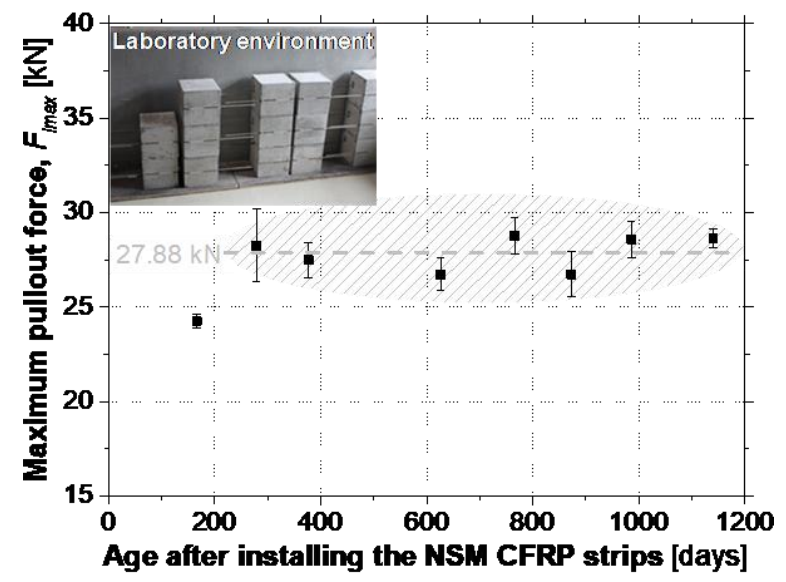

Figure 13: Evolution of the maximum pullout force for reference series throughout the exposure time. 
Fernandes, P.; Sena-Cruz, J.; Xavier, J.; Silva, P.; Pereira, E.; Cruz, J.R. (2018) "Durability of bond in NSM CFRP-concrete systems under different environmental conditions." Composites Part B, 138: 19-34.

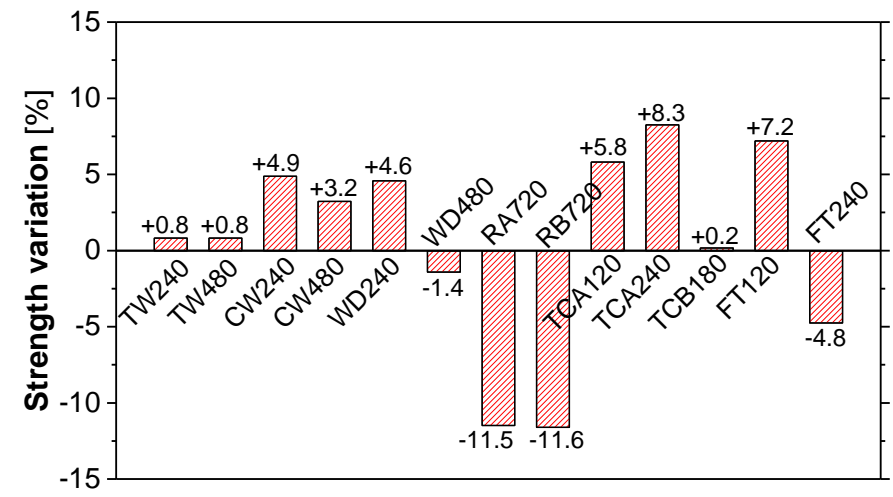

Figure 14: Maximum pullout force variation due to the effect of different environmental conditions. 
Fernandes, P.; Sena-Cruz, J.; Xavier, J.; Silva, P.; Pereira, E.; Cruz, J.R. (2018) "Durability of bond in NSM CFRP-concrete systems under different environmental conditions." Composites Part B, 138: 19-34.

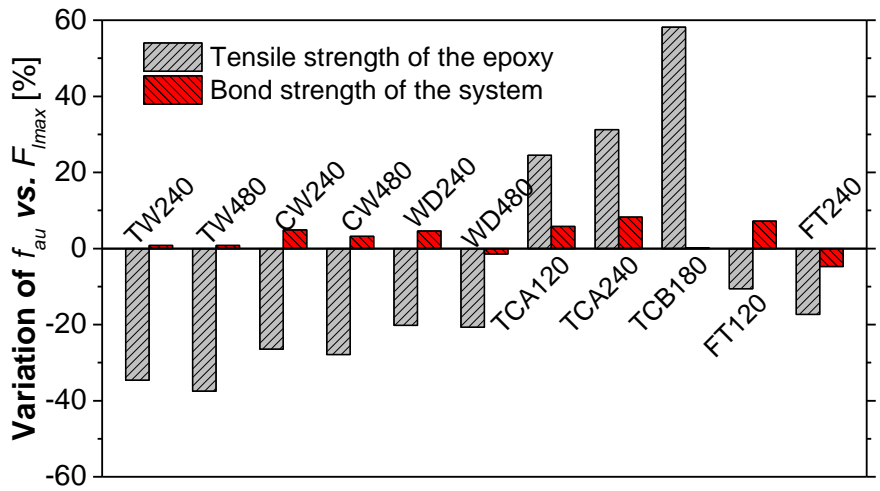

Figure 15: Comparison between the variations of the $f_{a u}$ of the epoxy and $F_{\text {lmax }}$ of the NSM CFRP-concrete system for distinct environmental conditions. 

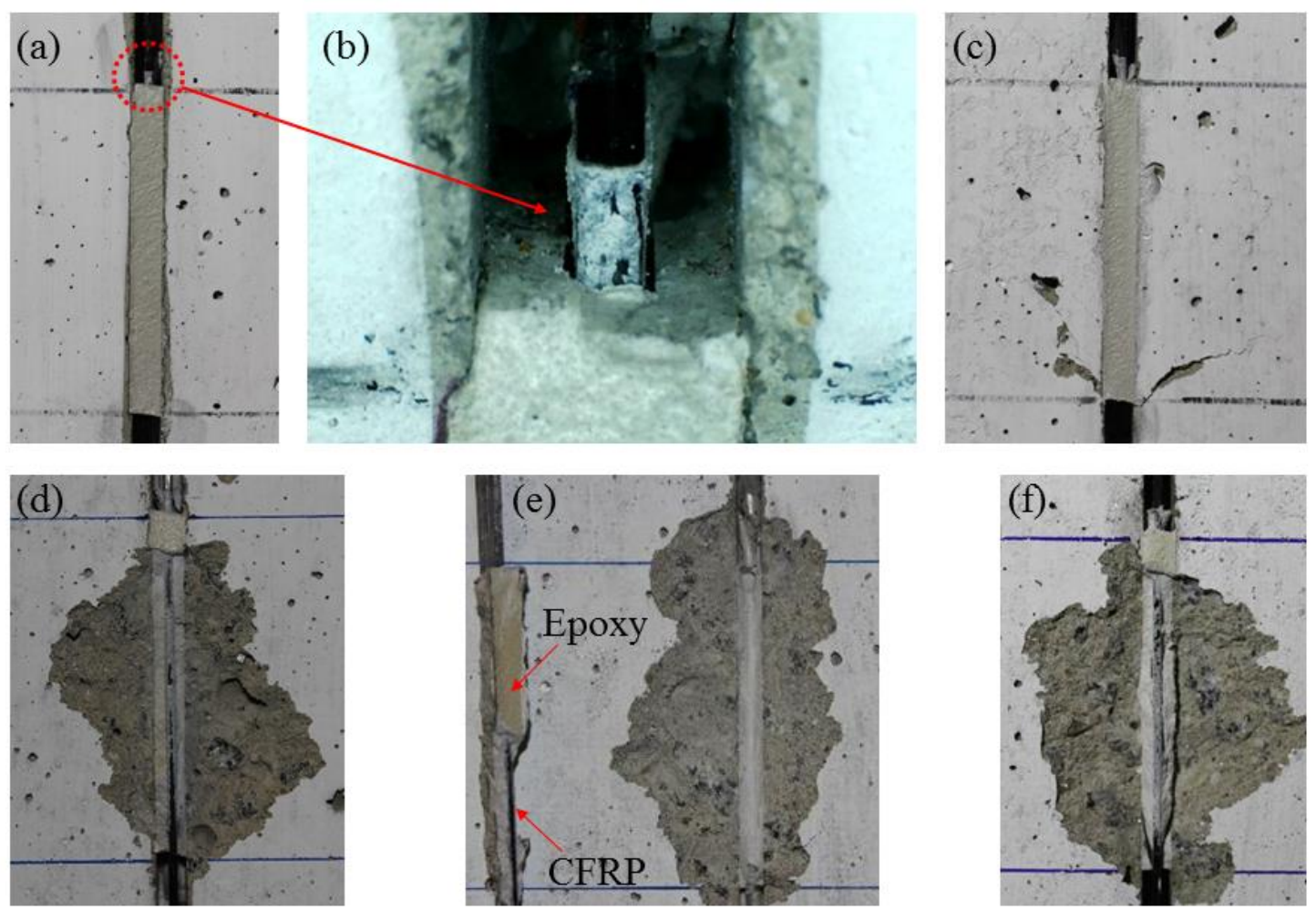

Figure 16: Observed failure modes: (a) and (b) I-FA: debonding at the interface CFRP/adhesive; (c) I-FA+CC: debonding at the interface CFRP/adhesive with concrete cracking; (d) I-FA+CS: debonding at the interface CFRP/adhesive with concrete splitting; (e) C-C: cohesive failure in concrete; (f) I-AC+CS: debonding at the interface adhesive/concrete with concrete splitting. 